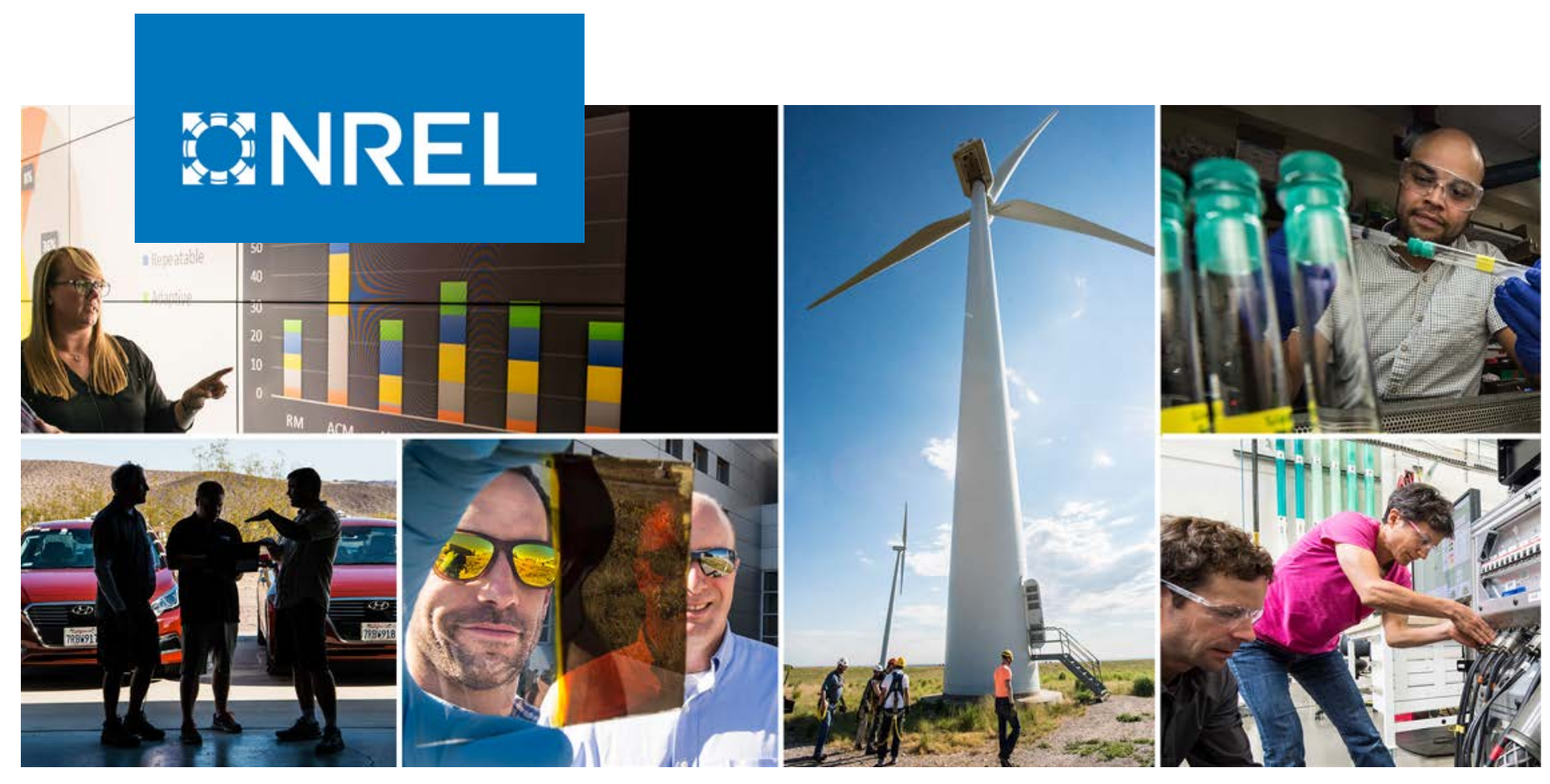

\title{
Wind and Solar Hybrid Power Plants for Energy Resilience
}

Caitlyn E. Clark, Aaron Barker, Jennifer King, and James Reilly

National Renewable Energy Laboratory

NREL is a national laboratory of the U.S. Department of Energy

Office of Energy Efficiency \& Renewable Energy

Operated by the Alliance for Sustainable Energy, LLC

This report is available at no cost from the National Renewable Energy Laboratory (NREL) at www.nrel.gov/publications.
Technical Report

NREL/TP-5R00-80415

January 2022 


\section{GNREL}

\section{Wind and Solar Hybrid Power Plants for Energy Resilience}

Caitlyn E. Clark, Aaron Barker, Jennifer King, and James Reilly

National Renewable Energy Laboratory

\section{Suggested Citation}

Clark, Caitlyn E., Aaron Barker, Jennifer King, and James Reilly. 2022. Wind and Solar Hybrid Power Plants for Energy Resilience. Golden, CO: National Renewable Energy Laboratory. NREL/TP-5R00-80415. https://www.nrel.gov/docs/fy22osti/80415.pdf.

NREL is a national laboratory of the U.S. Department of Energy Office of Energy Efficiency \& Renewable Energy Operated by the Alliance for Sustainable Energy, LLC

This report is available at no cost from the National Renewable Energy Laboratory (NREL) at www.nrel.gov/publications.

Contract No. DE-AC36-08GO28308
Technical Report NREL/TP-5R00-80415 January 2022

National Renewable Energy Laboratory 15013 Denver West Parkway Golden, CO 80401

303-275-3000 • www.nrel.gov 


\section{NOTICE}

This work was authored by the National Renewable Energy Laboratory, operated by Alliance for Sustainable Energy, LLC, for the U.S. Department of Energy (DOE) under Contract No. DE-AC36-08GO28308. Funding provided by the U.S. Department of Energy Office of Energy Efficiency and Renewable Energy Wind Energy Technologies Office. The views expressed herein do not necessarily represent the views of the DOE or the U.S. Government.

This report is available at no cost from the National Renewable Energy Laboratory (NREL) at www.nrel.gov/publications.

U.S. Department of Energy (DOE) reports produced after 1991 and a growing number of pre-1991 documents are available free via www.OSTI.gov.

Cover Photos by Dennis Schroeder: (clockwise, left to right) NREL 51934, NREL 45897, NREL 42160, NREL 45891, NREL 48097, NREL 46526.

NREL prints on paper that contains recycled content. 


\section{Acknowledgments}

We are thankful to all project team members from partnering laboratories on the Microgrids, Infrastructure Resilience, and Advanced Controls Launchpad (MIRACL) project:

- Idaho National Laboratory

- Pacific Northwest National Laboratory

- Sandia National Laboratories.

We also express our sincere gratitude to our industry advisory board members for their valuable insights and recommendations during the March 2020 advisory board meeting: Venkat Banunarayanan (National Rural Electric Cooperative Association), Chris Rose (Renewable Energy Alaska), Rob Wills (Intergrid), Paul Dockrill (Natural Resource Canada), Jeff Pack (POWER Engineers), Arvind Tiwari (GE Global Research), Kristin Swenson (Midcontinent Independent System Operator), Jonathon Monken (PJM), and Scott Fouts (QED Wind Power). In addition, we would like to thank Robert Preus, Dan Olis, Megan Culler, Craig Rieger, Andrew Reiman, Brian Smith, and Paul Veers for their thoughtful review, and Amy Brice and Sheri Anstedt for editorial support. Lastly, we would like to thank Paul Stackhouse and Bradley Macpherson for their assistance in using the NASA POWER tool for our Alaska analysis. 


\section{Executive Summary}

Wind-solar-storage hybrid power plants represent a significant and growing share of new proposed projects in the United States. Their uptake is supported by increasing renewable energy market share, enhanced technical abilities for dispatch and control, and decreasing costs for wind energy, solar energy, and battery storage. Simultaneously, there is also increased use of generation and storage resources in distributed power systems. The diversification of energy resources through hybridization or spatial distribution provides an opportunity to enhance power system resilience (compared to single-source generation), addressing growing concerns about the reliability of the aging, transforming U.S. electric grid. The question of where to build hybrid plants for resilience value-rather than for bulk power supply — has not been fully explored in previous studies. Therefore, in this study we complete a national complementarity analysis to identify areas in the United States that are particularly suited for wind-solar hybrid power plant development. The authors show the importance of seasonal and diurnal patterns in assessing complementarity and identify that regions in the Great Plains, Midwest, and Southeast are particularly suited for hybrid power plants. We demonstrate the resilience value of hybridization for a reference system based near Memphis, Tennessee, and show optimal sizing of wind, solar, and storage assets given 1.0 and 0.9 critical load factors. Our results indicate that the pairing of wind and solar assets better meets constant load demand and reduces storage requirements compared to using only solar assets. These results will enable future work to integrate complementarity metrics with resilience frameworks. The results also indicate a need for more finely resolved data for local resources, demand, and hazards. 


\section{Table of Contents}

Complementarity Metrics . . . . . . . . . . . . . . . . . . . . 4

Measuring Resilience . . . . . . . . . . . . . . . . . . . . . . . 5

Methods . . . . . . . . . . . . . . . . . . . . . . . . 7

Results . . . . . . . . . . . . . . . . . . . . . . . . . 11

$4.2 \quad$ Reference System Analysis . . . . . . . . . . . . . . . . . . . 12

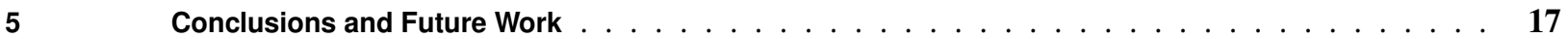

References . . . . . . . . . . . . . . . . . . . . . . . . . . . 18

Appendix A Annual Complementarity for 2013, Contiguous United States . . . . . . . . . . . . . . . . . . . . . 21

Appendix B Annual Average Wind Speed and Global Horizontal Irradiance for 2013, Contiguous United States . . 22

Appendix C Annual Complementarity for 2013, Hawaii . . . . . . . . . . . . . . . . . . . . . . . . . 23

Appendix D Annual Average Wind Speed and Global Horizontal Irradiance for 2013, Hawaii . . . . . . . . . . . . 24

Appendix E Annual Complementarity for 2013, Alaska . . . . . . . . . . . . . . . . . . . . . . . . . . . . 25

Appendix F Annual Average Wind Speed and Global Horizontal Irradiance for 2013, Alaska . . . . . . . . . . . 26

Appendix G Complementarity per Month, Contiguous United States . . . . . . . . . . . . . . . . . . . . . . . . 27

Appendix H Complementarity per Month, Hawaii . . . . . . . . . . . . . . . . . . . . . . . . . . . . . . . . 29

Appendix I Complementarity per Month, Alaska . . . . . . . . . . . . . . . . . . . . . . . . . 31

\section{List of Figures}

Figure 1 Geographic extent of complementarity analysis. Source: Image (O2021 Google, Map Data C2021 SIO, NOAA, U.S. Navy, NGA, GEBCO Landsat/Copernicus IBCAO INEGI SK telecom . . . . . . . . . . . .

Figure $2 \quad$ Location of reference system microgrid near Memphis, Tennessee. Source: Image @2021 Google, Map Data (2021 SIO, NOAA, U.S. Navy, NGA, GEBCO Landsat/Copernicus IBCAO INEGI SK telecom . .

Figure 3 Power curve for the 2.5-megawatt GE 2.5xl wind turbine. Source: System Advisory Model (National Renewable Energy Laboratory 2020) . . . . . . . . . . . . . . . . . . . . . . . . . . . 9

Figure $4 \quad$ SunPower photovoltaics module power curve . . . . . . . . . . . . . 10

Figure 5 Hybrid plant performance for Naval Support Activity Mid-South given a 0.9 critical

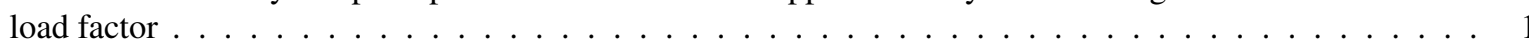

Figure 6 Hybrid plant performance for Naval Support Activity Mid-South given a 1.0 critical

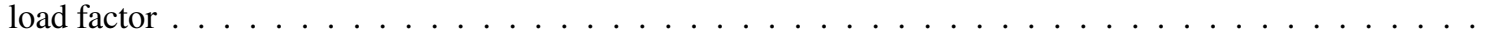

Figure Appendix A.1 Annual, daily-averaged complementarity (represented by the Pearson correlation metric) for 2013 in the contiguous United States . . . . . . . . . . . . . . . . . . . . . .

Figure Appendix A.2 Annual, hourly-averaged complementarity (represented by the Pearson correlation metric) for 2013 in the contiguous United States . . . . . . . . . . . . . . . . . . . . . . . .

Figure Appendix B.1 Average annual wind speed in meters per second (m/s) for 2013 in the contiguous United States 
Figure Appendix B.2 Average annual global horizontal irradiance (GHI) in watts per square meter $\left(\mathrm{W} / \mathrm{m}^{2}\right)$ for 2013 in the contiguous United States . . . . . . . . . . . . . . . . . . . . . . . . . 22

Figure Appendix C.1 Annual, daily-averaged complementarity (represented by the Pearson correlation metric) for 2013 in Hawaii . . . . . . . . . . . . . . . . . . . . . . . . . . . . . . . . . . . . . . . . . . 23

Figure Appendix C.2 Annual, hourly-averaged complementarity (represented by the Pearson correlation met-

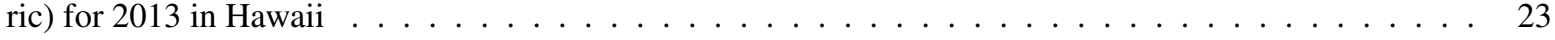

Figure Appendix D.1 Average annual wind speed (m/s) for 2013 in Hawaii . . . . . . . . . . . . . . . . . . . 24

Figure Appendix D.2 Average annual global horizontal irradiance $\left(\mathrm{W} / \mathrm{m}^{2}\right)$ for 2013 in Hawaii . . . . . . . . . 24

Figure Appendix E.1 Annual, daily-averaged complementarity (represented by the Pearson correlation metric) for 2013 in Alaska . . . . . . . . . . . . . . . . . . . . . . . . . . . . . . . . . . . . . .

Figure Appendix E.2 Annual, hourly-averaged complementarity (represented by the Pearson correlation metric) for 2013 in Alaska . . . . . . . . . . . . . . . . . . . . . . . . . . . . . . . . . . . . . . . . . .

Figure Appendix F.1 Average annual wind speed (m/s) for 2013 in Alaska . . . . . . . . . . . . . . . . 26

Figure Appendix F.2 Average annual global horizontal irradiance $\left(\mathrm{W} / \mathrm{m}^{2}\right)$ for 2013 in Alaska . . . . . . . . 26

Figure Appendix G.1 Daily-averaged complimentary (represented by the Pearson correlation metric) per

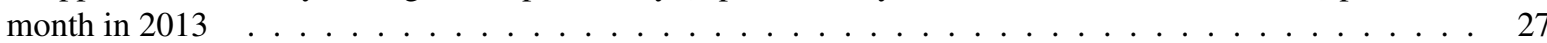

Figure Appendix G.2 Hourly-averaged complementarity (represented by the Pearson correlation metric) per month in $2013 \ldots \ldots \ldots \ldots$

Figure Appendix H.1 Daily-averaged complementarity (represented by the Pearson correlation metric) per month in $2013 \ldots \ldots \ldots \ldots \ldots$

Figure Appendix H.2 Hourly-averaged complementarity (represented by the Pearson correlation metric) per

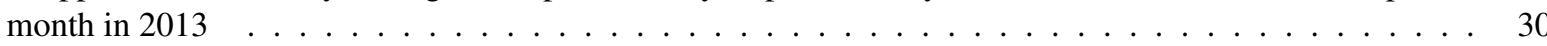

Figure Appendix I.1 Daily-averaged complementarity (represented by the Pearson correlation metric) per month in $2013 \ldots \ldots \ldots \ldots \ldots \ldots \ldots$

Figure Appendix I.2 Hourly-averaged complementarity (represented by the Pearson correlation metric) per month in 2013

\section{List of Tables}

Table 1

Table 2

Table 4

Table 3

Table 5
Geographic extent of complementarity analysis . . . . . . . . . . . . . 7

Wind Turbine Performance Characteristics . . . . . . . . . . . . . . . . . 9

Solar Plant Efficiency and Performance Details . . . . . . . . . . . . . . . . . . . 10

Solar Module Technical Details . . . . . . . . . . . . . . . . . . . . 10

Hybrid Optimization and Performance Platform Project Sizing Results . . . . . . . . . 13 


\section{Introduction}

The electric power industry is rapidly transforming, pushed by aging infrastructure, evolving customer needs, and environmental impact considerations, and pulled by technical advancements, favorable economic conditions, and supportive policy. Utilities seek to modernize grid infrastructure to enhance resilience and operational efficiency and integrate higher levels of distributed energy resources (both generation and storage) (U.S. Department of Energy 2017). Meanwhile, consumer control over energy costs and sources is increasing. Despite this rapid modernization, providing safe, reliable, and affordable electricity to critical infrastructure systems and customers remains a paramount priority (U.S. Department of Energy 2017; Obama 2013). In electric systems, "reliability" means that sufficient, uninterrupted electricity is provided to all customers in nominal operating conditions, or conditions for which that system was designed. For instance, one standard defines electric system reliability as the average likelihood of disconnecting customers to be no more than 1 day in 10 years. Electric systems, however, face threats that exceed nominal operating conditions, such as short-term natural hazards like wildfires, floods, and other extreme weather events, and human-made threats like physical attacks or cyberattacks. The ability of the power system to resist, respond to, and recover from these low-probability, high-impact extreme events defines the resilience of the system. As grid investments are made, solutions to improve efficiency and grid resilience should be considered, such as diversifying renewable generation sources (by combining wind turbines and solar photovoltaics through hybrid power plants), distributing generation throughout the grid, enhancing grid flexibility by adding storage, and implementing advanced controls.

Diverse, distributed generation and storage is inherently more resilient than a single, centralized generator. If a disruptive event occurs that compromises transmission or distribution lines, limits remote generation capacity, or causes cascading failures, the local availability of distributed power sources enables the system to better handle the disturbance. Factors like market expectations, policy priorities, and regulations (Orrell, Homer, and Tang 2018) make it difficult to assign a value to this enhanced resilience, but valuation is critical for stakeholders to compare distributed hybrid power plants to other grid infrastructure investments in resilience planning. This is especially true for hybrid power plants that combine solar, wind, and storage, given that regulation and market participation of these plants is uncertain (Gorman et al. 2020). Often, large wind- or solar-only power plants are sited based on the strongest available resource, which is not necessarily an optimal method for maximizing hybrid plant resilience benefits. Instead, hybrid power plant siting, especially when considering resilience and efficiency objectives, should consider 1) where the renewable resources are complementary (or noncoincident), 2) where the generated energy can be used locally, and 3) where batteries can provide the most grid benefits (which depends not just on battery placement but also on the ability to participate in capacity markets). To optimally site hybrid power plants and understand their resilience value to the grid, we need to first identify regions where renewable resources are complementary and develop metrics that account for their hybrid and distributed-asset resilience value.

The purpose of this study is to develop a method to identify areas in the United States where wind and solar hybrid plants can provide enhanced resilience value to distributed grid systems via complementary resources. We achieve this through two objectives. First, we aim to determine appropriate resilience metrics that can be used to measure resilience benefits of hybrid and distributed resources at the local or grid level. Second, we aim to identify where those benefits can be best realized from a national resource analysis. To achieve these objectives, we identify regions in the United States where wind and solar resources are complementary and thus are better at providing resilience benefits. Then, we analyze a reference system near Memphis, Tennessee, to investigate how these hybrid plants and their generation would be integrated and dispatched to support increased system resilience. This study is part of a multiyear effort across laboratories aimed at identifying the challenges and opportunities in valuing and integrating distributed wind turbines with solar photovoltaics and energy storage systems for resilience (Reilly 2020). Section 2 describes relevant complementarity and resilience metrics that account for the resilience value of hybrid or distributed renewable energy assets. The methods used for resource complementarity quantification and reference system analysis are described in Section 3. Section 4 discusses the results of the resource complementarity mapping and describes the resilience value within the selected reference system. Section 5 highlights the main findings of this study and describes directions for future work to realize the resilience benefits of hybrid power plants at a distributed scale. 


\section{Literature Review}

By hybridizing or spatially distributing renewable energy generation assets, the complementarity of the distinct resources can be leveraged to provide energy and grid services more reliably than any of the assets can on their own. Complementarity can be achieved by co-locating generation assets or by creating virtual power plants (coordinating distributed, electrically connected assets). Previous studies have assessed complementarity as a means of overcoming the historical reliability shortcomings of renewable energy generation in transmission systems.

Although similar concepts, reliability and resilience are different in two distinct ways. First, reliability is an outcome (for example, maintaining sufficient electricity to all customers), whereas resilience is a characteristic of the system that enables it to achieve that outcome (for example, the ability of a system to return power to customers after a blackout). Second, reliability refers to an outcome in nominal conditions, or conditions for which the system was designed, and resilience is a characteristic of the system in extreme conditions, or conditions that exceed design expectations. Thus, metrics that measure the reliability of a system can also measure the effectiveness of a resilient system, contingent on the presence of a disruptive event. For instance, loss-of-load probability is a common metric used in reliability standards. When applied in the context of resilience, loss-of-load probability implies a system's ability to resist a disruption and provide reliable electric service.

Previous studies have defined reliability metrics and applied them in a resilience context. Few studies, however, have considered complementarity as a means of improving resilience in distributed systems. Leveraging resource complementarity could provide systems with a greater ability to resist, respond to, or recover from load loss during an extreme event, thus providing resilience value to the system. This is particularly important in smaller systems with fewer distributed generation assets and therefore less redundancy. Metrics are needed that 1) quantify resource complementarity to identify opportunities for hybrid power plant development and 2) can be used in conjunction with resilience frameworks to compare distributed hybrid power plants with other grid resilience investments. In this section, we determine the most appropriate metrics for quantifying the resilience value of distributed and hybrid generation assets to be used in hybrid plant design at the local or distributed grid scale.

\subsection{Complementarity Metrics}

Previous studies that analyze complementarity often focus on siting and sizing hybrid plants based on hourly or subhourly time series data. These studies frequently measure complementarity via statistical correlation metrics or reliability metrics (Jurasz et al. 2020). Correlation metrics provide insight to resource dependence and are best used to assess hybrid potential from a resource perspective when paired with absolute resource availability. Reliability metrics directly measure how adequate resource complementarity and availability are to meet a load. Although reliability metrics provide a direct way to measure the outcome of a distributed hybrid system's resilience, they require system-specific load data and thus are not suitable for regional or national complementarity analyses.

Pearson's correlation coefficient, $r$, is the most popular statistical metric used in complementarity analysis. It is used to 1) measure the potential for a hybrid system to efficiently provide generation capacity in renewable energy systems (Li, Agelidis, and Shrivastava 2009; Liu et al. 2013; Miglietta, Huld, and Monforti-Ferrario 2016; VegaSanchez et al. 2017; Shaner et al. 2018; Slusarewicz and Cohan 2018), 2) optimize hybrid systems design (Jurasz, Beluco, and Canales 2018a), and 3) optimize dispatch and operations of existing solar and wind generation assets on a grid (Aza-Gnandji et al. 2018; Naeem et al. 2019). Other metrics are used for similar applications, including the Kendall rank correlation coefficient, $\tau$ (Xu, Wang, and Liu 2017; Ren et al. 2019), cross-correlation (Li, Agelidis, and Shrivastava 2009; Dos Anjos et al. 2015), and author-defined metrics.

Metrics that relate complementarity to hybrid or distributed system reliability often measure loss of load, power fluctuations, or power smoothing. Loss-of-load probability has been used to assess enhanced system reliability from distributed wind assets (Kahn 1979), complementary solar and wind resources (Jurasz, Beluco, and Canales 2018b), and distributed wind and solar resources (Shaner et al. 2018). Schmidt, Cancella, and Pereira applied this loss-of-load probability metric as a constraint to optimize the size and composition of solar, wind, and hydropower resources to meet demand (Schmidt, Cancella, and Pereira 2016). Electrical output fluctuations have also been used as a reliability metric for complementary wind and solar resources (Gburcik et al. 2006) and distributed photovoltaics plants (Murata, Yamaguchi, and Otani 2009; Marcos et al. 2012). Widén considered output fluctuation reduction from wind and solar energy generation under minor disturbance events, such as clouds passing over solar 
arrays (Widén 2015). Ramp rate, or how quickly power output changes over time, is also used as a complementarity metric. Ramp rate is used to enable supply and demand balancing, prevent grid effects from rapid loading or discharge, and prevent the draining of system reserves (Tarroja, Mueller, and Samuelsen 2013; Widén 2011; Zhang et al. 2018). The ability of a hybrid or distributed system to reduce fluctuations or ramp rate could be used to measure the added resilience value from grid investments if scaled to consider extreme events.

Power smoothing has also been used in complementarity analyses to measure the added value of assets to system reliability. Power smoothing leverages the variations in generation output across spatially distributed generation assets to provide adequate power during minor disruptive events, such as periods of low wind power production. Previous studies leveraged national or regional analyses to attain maximum smoothing. Small distribution systems may not have the same potential for power smoothing given their geographical extent, but if a system has little load, it could be possible to leverage even small amounts of power smoothing through distribution to achieve greater system resilience. In a resilience context, where low-probability events could cause a proportionally large loss in generation capacity, the ability to ride through events becomes demand-dependent (i.e., what is the level of demand, and how much of it is critical). The concept of power production during critical time windows, or events with lower-thanaverage capacity factors, is proposed by Berger et al.. They consider spatiotemporal complementarity, measuring the time during which renewable energy generation passes below a particular threshold during events of low wind power production (Berger et al. 2020). Sterl et al. extend this metric to the power smoothing value of hybrid power plants. They propose a stability coefficient that measures the added value of using additional solar and wind energy capacity to balance daily power output (Sterl et al. 2018).

\subsection{Measuring Resilience}

Efforts to measure distributed power system resilience often rely on reliability metrics but apply them through different phases of a disturbance event to measure how well a system resists, responds to, recovers from, or restores after a disturbance. Resilience frameworks are used in some instances to distinguish the phases of the disturbance event. While an extensive body of research exists for resilience framework development and validation, this review focuses on resilience metrics that can be used regardless of the framework employed.

The ability of power systems to supply load (similar to the loss-of-load probability metric) is often used as the metric to quantify resilience in electricity systems. McJunkin and Rieger define metrics for adaptive capacity (the available active and reactive power at a node that could be injected if necessary in response to a disturbance) and insufficiency (the inability of that node to supply active and reactive power when necessary) (McJunkin and Rieger 2019). They also define "resilience threshold," which delineates when a power system transitions between performing satisfactorily and unsatisfactorily given a disturbance and mirrors the threshold concept proposed by Berger et al. (Berger et al. 2020). Cicilio et al. incorporate uncertainty from hazard probability and electrical component performance into their resilience evaluation, using "energy not served" as their metric, while also introducing a resilience framework to compare resilience improvements and derate a system's resilience over time. This methodology accounts for the resilience stages of the event originally defined by Tierney and Bruneau (Tierney and Bruneau 2007) and the resilience threshold under various hardening improvements. Cicilio et al. use "energy not served" as the performance metric to evaluate overall system resilience (Cicilio et al. 2020).

In microgrid system resilience quantification, metrics frequently go beyond load-not-served metrics, such as adaptive capacity and energy not served, to encompass metrics that measure the self-sufficiency of the system, the ability of the system to persist through a hazard or extreme event, and the amount of fuel used to amend system generation to meet load (Nelson et al. 2020). Reiman et al. define metrics for energy use efficiency and ride-through ability to quantify resilience benefits from distributed and hybrid energy resources that normally go unacknowledged in the energy markets (Reiman et al. 2020). Marginal local energy usage efficiency represents the distributed energy both produced and consumed behind the meter, which minimizes the energy required to be purchased from the grid at the full retail electricity rate. This is especially important if the grid is experiencing high electricity rates because of a disturbance event, or if a segment of the grid is islanded. Marginal combined energy usage efficiency indicates the ability of a segment of the grid to contribute energy to the larger grid and potentially serve critical loads. The incremental sustainable ride-through energy ratio describes the ability of a microgrid to serve critical load during an outage, which depends on the combined availability of variable distributed generation and storage. This ratio could be used to optimally size and site distribution-scale hybrid systems for maximum resilience value. 
Whereas previous research has advanced our ability to measure and compare the added value of hybrid or distributed energy assets on system resilience, we need to first understand where wind and solar resources are complementary. Previous work focused on U.S. resources has considered 1) site-specific hybrid complementarity or 2) spatial distribution of a single generation technology. A national analysis that highlights hybrid opportunity areas where wind and solar resources are complementary does not exist. 


\section{Methods}

This work aims to identify areas in which there is enhanced opportunity to realize the resilience benefit of hybrid systems by analyzing the complementarity of wind and solar resources across the United States. We demonstrate how this complementarity analysis can be paired with local analysis to evaluate the resilience benefit of distributionlevel hybrid power plants through a particular reference system: a microgrid near Memphis, Tennessee.

The national complementarity analysis was completed for the contiguous United States (CONUS), Hawaii, and Alaska for the year 2013. The spatial extent and resolution of the data sampling for wind and solar resources for the analysis are detailed in Figure 1 and Table ??.

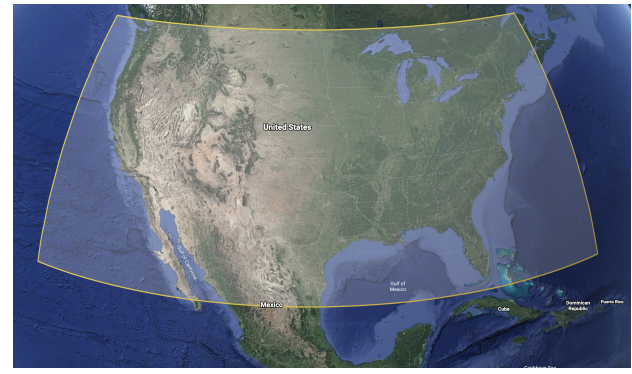

(a) Contiguous United States

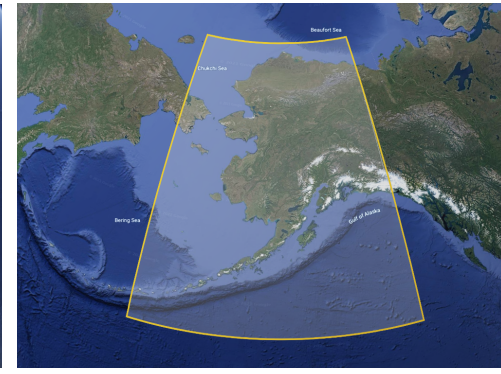

(b) Alaska

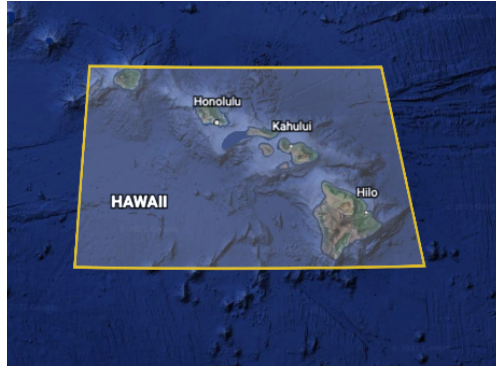

(c) Hawaii

Figure 1. Geographic extent of complementarity analysis. Source: Image $\bigcirc 2021$ Google, Map

Data @2021 SIO, NOAA, U.S. Navy, NGA, GEBCO Landsat/Copernicus IBCAO INEGI SK telecom

Table 1. Geographic extent of complementarity analysis

\begin{tabular}{|c|c|c|}
\hline Area & $\begin{array}{c}\text { Latitude } \\
\text { (min, max, no. points) }\end{array}$ & $\begin{array}{c}\text { Longitude } \\
\text { (min, max, no. points) }\end{array}$ \\
\hline CONUS $^{\mathrm{a}}$ & $(23.8,49.3,42)$ & $(-129.2,-65.7,164)$ \\
Alaska & $(50.0,72.0,60)$ & $(-160.2,-154.7,60)$ \\
Hawaii & $(22.2,18.7,6)$ & $(-175.0,-130.0,15)$ \\
\hline
\end{tabular}

${ }^{\text {a }}$ CONUS $=$ Contiguous United States

For each location within CONUS and Hawaii, the Wind Integration National Dataset Toolkit (WIND Toolkit) (Draxl et al. 2015) was used to collect hourly wind speed and direction data at an assumed hub height of 100 meters (m). Global horizontal irradiance (GHI) data were used as a representative metric for total solar resource and were collected hourly for each location within CONUS and Hawaii from the National Solar Radiation Database (Sengupta et al. 2018). Because of data limitations at the time of this study, the National Aeronautics and Space Administration (NASA) Prediction of Worldwide Energy Resources (POWER) Project was used to collect wind and solar resource data in Alaska (NASA 2021). NASA POWER uses satellite data and data from the Modern-Era Retrospective analysis for Research and Applications, Version 2 (MERRA-2) as the basis of their platform, so there are discrepancies between the Alaska data and the rest of the data used in this study, but the same metrics were used to measure each resource. Wind speed and direction were measured at 50-m hub heights for the Alaska wind data, and GHI was calculated via Eq. 1:

$$
G H I=D H I+D N I * \cos (Z)
$$

where $D H I$ is the diffuse horizontal irradiance, $D N I$ is the direct normal irradiance, and $Z$ is the solar zenith angle. We assume ground-reflected radiation is insignificant compared to direct and diffuse radiation.

Using wind speed and GHI, complementarity was measured by calculating the Pearson $r$ coefficient using Eq. 2:

$$
r=\frac{\sum(x-\bar{x})(y-\bar{y})}{\sqrt{\sum(x-\bar{x})^{2} \sum(y-\bar{y})^{2}}}
$$

where $\bar{x}$ is the mean of the vector $x, \bar{y}$ is the mean of the vector $y$, and the vectors $x$ and $y$ represent the wind and solar data, respectively. The resulting Pearson $r$ coefficient is on a scale from -1 to 1, with a score of -1 representing perfect negative correlation, a score of 0 representing no correlation, and a score of 1 representing perfect positive 
correlation. A perfect positive correlation means that the wind and solar resource profiles occur at the same time in a given location, while a perfect negative correlation means that the wind and solar resource profiles are perfectly complementary, occurring inversely at a given location.

Complementarity was measured over four time scales: annual versus monthly, and daily-averaged versus hourlyaveraged:

1. The annual, daily-averaged complementarity metric calculates a Pearson $r$ coefficient across the 24 hourly wind and solar resource values for each day in 2013, and then averages those 365 values for a single, annual value. The annual, daily-averaged complementarity metric does not consider seasonal or diurnal patterns but gives a general indication for overall complementarity of a given location for sizing and siting considerations.

2. The annual, hourly-averaged complementarity metric calculates the complementarity for every hour in 2013 , and averages those 8,760 values over the year. The annual, hourly-averaged complementarity metric does not consider seasonality but does consider diurnal patterns.

3. The monthly, daily-averaged complementarity metric calculates a Pearson $r$ coefficient across the 24 hourly wind and solar resource values for each day and averages those values over each month (approximately 30 values), resulting in 12 seasonally dependent complementarity values.

4. The monthly, hourly-averaged complementarity metric calculates the Pearson $r$ coefficient for each hour and averages those values over each month (approximately 720 values). This method results in a metric that considers season and diurnal patterns and is well-suited for assessing the resource ability to serve hourly demand or other grid services.

Although this study focuses on a national complementarity analysis for the United States, complementarity and hybrid power plant ability to meet system demand are sensitive to local conditions (especially at the distribution level). Thus, after we completed a complementarity analysis to identify regions where the resources are especially conducive to hybrid power plant development, we selected a reference system in an opportunity area to demonstrate hybridization of generation assets in a specific, highly complementary system. The chosen system for this analysis is in the southeastern United States, less than 20 miles north of Memphis, Tennessee (Figure 2). It was selected because of the presence of a microgrid and local interest in enhancing grid resilience in the area.

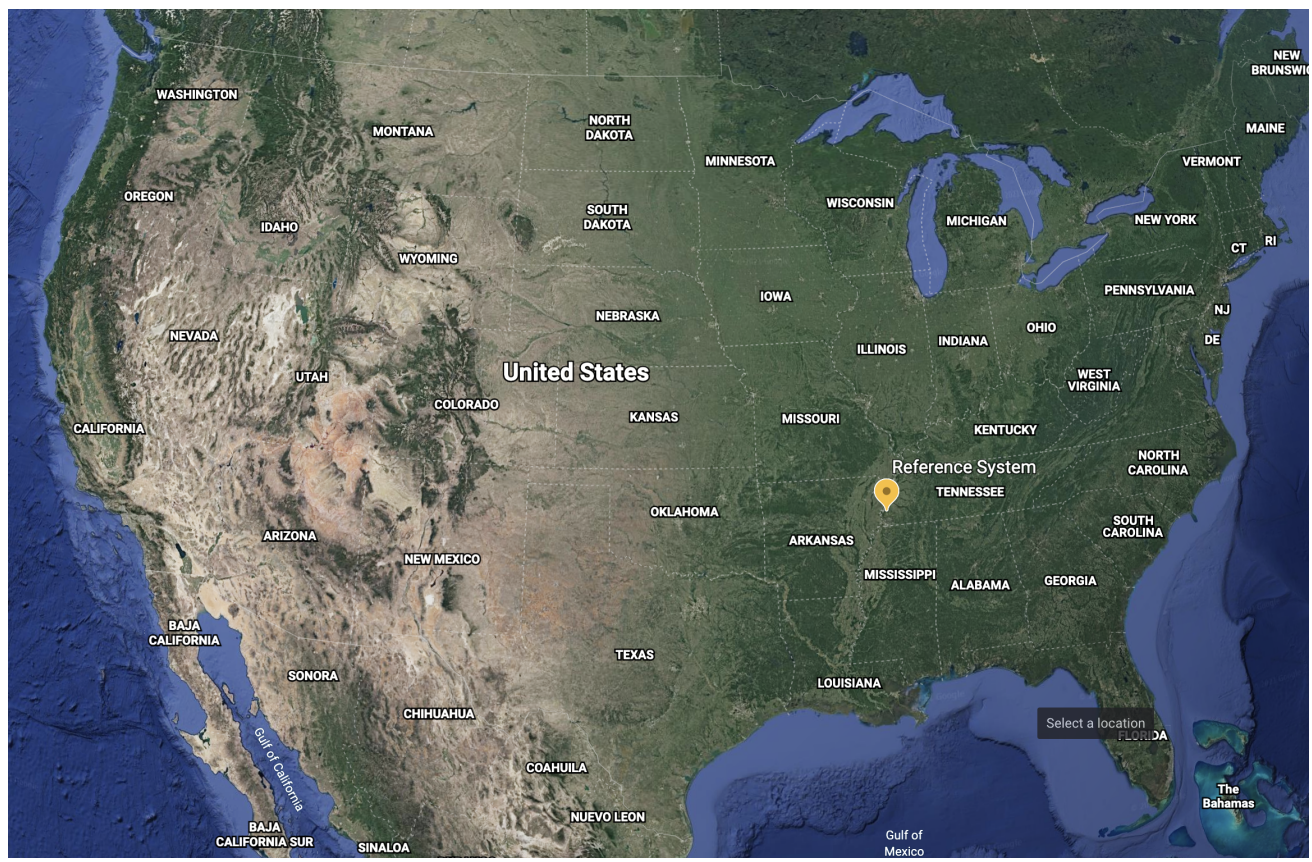

Figure 2. Location of reference system microgrid near Memphis, Tennessee. Source: Image $\bigcirc 2021$ Google, Map Data O2021 SIO, NOAA, U.S. Navy, NGA, GEBCO Landsat/Copernicus IBCAO INEGI SK telecom 
A representative daily profile for wind and solar generation was determined by averaging the resource profile for each day in 2013. We then used REopt ${ }^{\circledR}$ (Cutler et al. 2017), the Renewable Energy Integration and Optimization platform from the National Renewable Energy Laboratory (NREL) to determine the optimal size and mix of technologies for a wind-solar-storage plant. The Hybrid Optimization and Performance Platform (HOPP) (National Renewable Energy Laboratory 2021b) was used to design and analyze the plant at the component level, giving cost and value estimates for the plant. The hybrid plant sizing was completed for critical load factor values of 1.0 and 0.9 , representing minimum load targets of $100 \%$ and $90 \%$ of the design load, respectively. The technology cost assumptions used for sizing are based on NREL's Annual Technology Baseline 2025 (National Renewable Energy Laboratory 2021a) data for the "moderate" 2025 technology innovation category and are as follows: $\$ 1,492$ per kilowatt ( $\mathrm{kW}$ ) for wind; $\$ 1,095 / \mathrm{kW}$ for solar; and $\$ 179 / \mathrm{kW}$ and $\$ 206$ per kilowatt-hour $(\mathrm{kWh})$ for battery energy storage rate and storage capacity, respectively.

The wind turbine used in this analysis is a GE 2.5xl, 2.5-megawatt (MW) unit, with parameters that are determined through the NREL System Advisor Model (National Renewable Energy Laboratory 2020) default model generator. The wind turbine exhibits the key performance characteristics displayed in the power-performance curve (Figure 3) and the additional performance characteristics in Table 2.

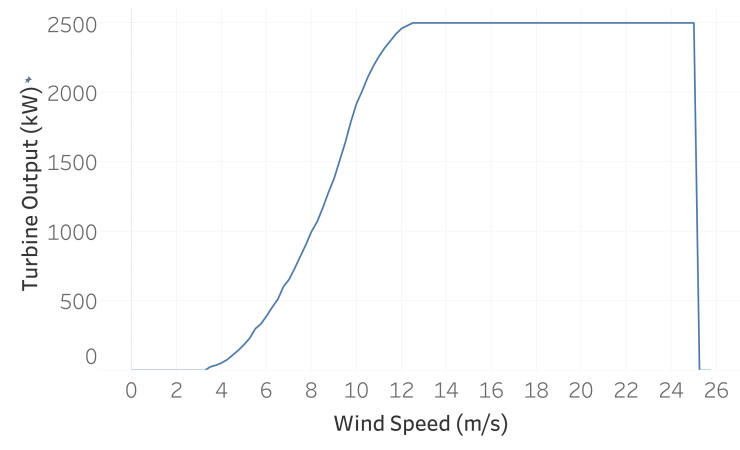

Figure 3. Power curve for the 2.5-megawatt GE 2.5xl wind turbine. Source:

System Advisory Model (National Renewable Energy Laboratory 2020)

Table 2. Wind Turbine Performance Characteristics

\begin{tabular}{|l|c|}
\hline Parameter & Value \\
\hline Maximum Rated Power (MW) & 2.5 \\
Cut-In Speed (m/s) & 4 \\
Cut-Out Speed (m/s) & 25 \\
Hub Height (m) & 80 \\
Rotor Diameter (m) & 100 \\
\hline
\end{tabular}

By default for utility-scale projects, the System Advisor Model selects the SunPower SPR-E19-310-COM photovoltaics module, a nonbifacial monocrystalline silicon panel with specifications as detailed in Table 3 , and module current/voltage curve given in Figure 4. 
Table 4. Solar Plant Efficiency and Performance Details

\begin{tabular}{|l|c|}
\hline Parameter & Value \\
\hline Solar Albedo (ratio) & 0.2 \\
AC Wiring Loss (\%) & 1 \\
DC Wiring Loss (\%) & 2 \\
Diode Connection Loss (\%) & 0.5 \\
Mismatch Loss (\%) & 2 \\
Nameplate Loss (\%) & 0 \\
Soiling Loss (\%) & 5 \\
DC Degradation (\%) & 0.5 \\
Azimuth (degrees) & 180 \\
Ground Coverage Ratio (ratio) & 0.3 \\
Tilt (degrees) & 20 \\
Module Aspect Ratio (ratio) & 1.7 \\
Inverter DS Efficiency (\%) & 96 \\
Inverter PD Efficiency (\%) & 95 \\
\hline
\end{tabular}

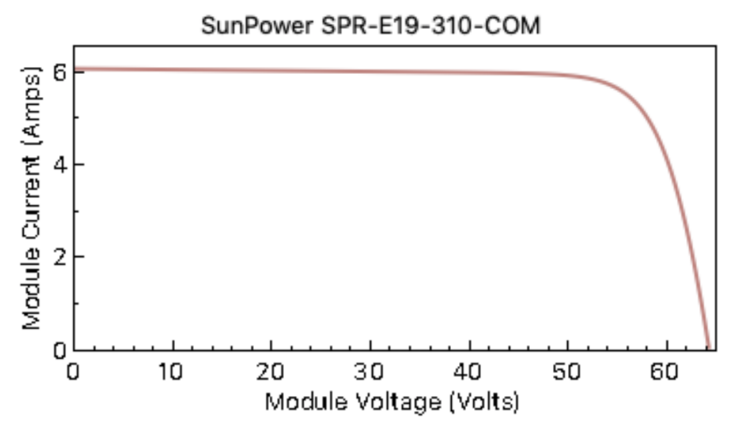

Figure 4. SunPower photovoltaics module power curve

Table 3. Solar Module Technical Details

\begin{tabular}{|l|c|}
\hline Parameter & Value \\
\hline Nominal Efficiency $(\%)$ & 19.02 \\
Maximum Power $\left(P_{M P}\right)$ (watts) & 310.15 \\
Maximum Power Voltage $\left(V_{M P}\right)$ (volts) & 54.7 \\
Maximum Power Current $\left(A_{M P}\right)(\mathrm{amps})$ & 5.7 \\
Open Circuit Voltage $\left(V_{O C}\right)($ volts $)$ & 64.4 \\
\hline
\end{tabular}

The total system is sized using these modules and then assumes a perfect inverter, which is sized to match the total number of modules and strings required to reach the desired solar install capacity. By default, the System Advisor Model chooses the SMA America SC750CP-US inverter, which is rated at 770 kilowatts $(\mathrm{kW})$ of AC power per inverter, and a DC-to-AC ratio of 1.2. Table 4 describes overall plant performance characteristics and assumptions for system efficiency and losses.

With the assumption that there was no land constraint, the ground coverage ratio of the project was set to 0.3 . Accordingly, self-shading was no longer a constraint in the system design discussed earlier. This key assumption helped reduce the total simulation time by avoiding a complex calculation of self-shading losses. 


\section{Results}

In this section, we first discuss the national complementarity analysis based on the methods covered in Section 3 and then follow with a more detailed analysis using our selected real-world reference system located north of Memphis, Tennessee.

\subsection{Complementarity Mapping}

The figures in the appendices depict the national complementarity analyses. Data are displayed by region as well as by whether they are annual or seasonal, and whether they are averaged daily or hourly. In addition to the complementarity analyses, we have included figures depicting annual average wind speed and GHI (Appendices Appendix B, Appendix D, and Appendix F) to convey the relative abundance of each resource in the given location. Resources that are abundant enough to meet local demand and complementary indicate an opportunity to build hybrid power plants for enhanced resilience.

It is important to note again that the Alaska results are based on different data than those used for CONUS and Hawaii. Therefore, the results from these two data sets should not be directly compared.

\subsubsection{Contiguous United States}

Annual analyses for CONUS (both daily- and hourly-averaged) are provided in Appendix Appendix A and monthly analyses are provided in Appendix Appendix G. Figures Appendix A.1 and Appendix A.2 show that in areas with complex terrain, such as the Appalachian area in the Northeast and mountainous areas in the West, there is lower complementarity. Areas of higher annual complementarity include the Great Plains, East Texas, the Midwest, and nonmountainous regions of the Northeast. In the daily-averaged analysis (Figure Appendix A.1), there are fewer regions of the United States that are complementary compared to the annual, hourly-averaged analysis (Figure Appendix A.2), indicating a need to use hourly-averaged analyses to fully account for the ability of hybrid resources to meet hourly local demand. When considering wind and solar resource abundance (Appendix Appendix B), areas in the Southwest, Great Plains, and Great Lakes regions have resources that could meet local demand. There are additional regions in the Southeast and West that have relative resource abundance; however, given the spatial variability of these regions, more detailed local or regional resource and complementarity analyses are needed.

Monthly analyses for CONUS are included in Appendix Appendix G, with the daily-averaged analysis in Figure Appendix G.1 and the hourly-averaged analysis in Figure Appendix G.2. The daily-averaged plots echo the trends of the annual analysis, with regions in the Midwest, Southeast, and nonmountainous Northeast having high resource complementarity, and western regions having more spatially variable complementarity. The temporal variability of complementarity is apparent across all regions, indicating that seasonal changes of wind and solar resources are a major influence on complementarity. The hourly-averaged analyses show trends that are less temporally variable, with most of the nonmountainous regions of the United States showing some complementarity. The West, again, is more spatially variable than the East. In the summer months, the complementarity trends intensify, with correlated areas becoming more correlated, and complementarity areas becoming more complementary. Areas in the Southeast and Midwest as well as those in California's Central Valley show particularly high complementarity during summer months. Mountainous regions, again, are less complementary (for example, regions in the Rocky Mountains, the Appalachian Mountains, the western coastal ranges, the Cascade Mountains, and the Sierra Nevada) and become more so during summer months. This trend intensification (correlated areas becoming more correlated and complementarity areas becoming more complementary) during summer months is thought to be caused by the seasonal changes in diurnal patterns for solar energy, namely, the increase in solar irradiance during summer months attributable to longer days and fewer cloudy days.

\subsubsection{Hawaii}

In Hawaii, annual analyses (both daily- and hourly-averaged) are provided in Appendix Appendix C and monthly analyses in Appendix Appendix H. For the annual, daily-averaged analysis (Figure Appendix C.1), areas of high complementarity include the center of Kauai, the eastern regions of Oahu, and the west coast of the Island of Hawaii. These regions of complementary resources, however, are not reflected in the hourly-averaged analysis in Figure Appendix C.2, which instead shows few, if any, regions with complementary resources. When considering resource 
abundance in Appendix Appendix D, annual average wind speed is fairly consistent across the islands (Figure Appendix D.1), whereas the annual average GHI is spatially more variable across the islands (Figure Appendix D.2). Areas of the islands where annual average GHI is low coincide with areas where complementarity is high. Given the spatial extent of the resources, distributed generation assets could take advantage of complementary resources while also leveraging high-resource areas to add power production. Monthly analyses for Hawaii are included in Appendix Appendix H, with the daily-averaged analysis in Figure Appendix H.1 and the hourly-averaged analysis in Figure Appendix H.2. The daily-averaged analysis indicates seasonal variance in complementarity, with more regions that have complementary resources and intensification of that complementarity in fall (September, October, November) and spring (April, May, June), and fewer regions with complementary resources in summer (July, August) and winter (December, January, February, and March). When observing the hourly-averaged analysis, most of Hawaii is correlated rather than complementary. Overall, Hawaii has abundant wind and solar resources, but they are not complementary on an hourly scale. Thus, Hawaii's resources are more suited for bulk power production and less suited for providing resilience value.

\subsubsection{Alaska}

In Alaska, annual analyses (both daily- and hourly-averaged) are provided in Appendix Appendix E and monthly analyses are provided in Appendix Appendix I. In the annual, daily-averaged analysis (Figure Appendix E.1), most regions in Alaska have complementary resources. In the annual, hourly-averaged analysis (Figure Appendix E.2), however, the correlation coefficient becomes more positive, with only coastal regions and some areas in the interior and south-central regions showing complementarity. The data indicate that it is especially important to consider diurnal patterns in Alaska when leveraging the complementarity of wind and solar resources for improved resilience value in generation assets.

Monthly analyses for Alaska are included in Appendix Appendix I, with the daily-averaged analysis in Figure Appendix I.1 and the hourly-averaged analysis in Figure Appendix I.2. Whereas complementarity trends in the dailyaveraged analysis are less spatially variable than those in some of the western regions of CONUS, they are more temporally variable, with the same regions fluctuating between positive and negative correlation from month to month. The hourly-averaged analysis shows few regions of complementarity; they mostly occur during winter months when the solar resource is especially low. The spatial and temporal variability indicates that multiple factors are interacting to influence these seasonal patterns.

The influence of diurnal patterns is pronounced in Alaska because of dramatic changes in daylight hours during the year. Seasonal changes in daylight and solar resource are evident in Appendix Appendix I. Figure Appendix I.1 shows the daily-averaged complementarity per month; the data indicate high temporal variability. In the plots in Appendix Appendix I, it is important to note the gray area in North Alaska in December, which indicates a lack of solar data as a result of a lack of sunlight. The changing amount of daylight influences the resource in other months, so that even if a site has complementary resources, it may not have enough solar resource abundance during certain parts of the year to support local demand. The hourly-averaged data, which take into account the diurnal patterns, indicate a less variable complementarity trend. Wind and solar resources are most complementary in specific regions in the winter months and become less complementary during summer months as the solar resource increases significantly (Figure Appendix I.2). This pattern is particularly important when considering energy use. In some regions in Alaska, demand is driven by heat consumption during cold months rather than by air-conditioning consumption during warm months, as is common in other parts of the United States. This demand pattern would result in the peak demand occurring in the months with minimal solar resource. On the contrary, there are also regions in Alaska that experience peak demand during months of high fishery or cruise ship activity, which would result in a better alignment of demand with solar resource availability. In Alaska, more detailed, local analysis that incorporates demand data is required to assess if hybrid power plants can meet local demand.

\subsection{Reference System Analysis}

In this section, we complete a detailed local analysis based on both resource and demand data for a microgrid north of Memphis, Tennessee. The site is at Naval Support Activity Mid-South and includes a 12-MW direct-current solar array that supplies electricity both to the site and to other Tennessee Valley Authority customers in the area. This site is of particular interest from a resilience perspective because it was built with resilience objectives in mind. The Navy estimates that when solar resource is available, the array could power 1,300 homes in addition to alongside 
mission-critical operations at the site. Additionally, the solar array is part of a larger installation that has a total direct current capacity of $53 \mathrm{MW}$.

To demonstrate the potential resilience benefit of hybridization in a distributed-level generation site, we consider a scenario in which Naval Support Activity Mid-South generates its required power via wind and solar assets with storage capacity. Figure 5 assumes a 0.9 critical load factor scenario, wherein the hybrid power plant is optimized to meet $90 \%$ of the load with renewable energy generation. The remaining load is met with diesel generation. Figure 6 assumes a 1.0 critical load factor scenario, or a scenario in which $100 \%$ of the load is met with the hybrid power plant. We assumed a constant load of $10 \mathrm{MW}$ for the purposes of this study, although in reality, $10 \mathrm{MW}$ is probably closer to the peak load of the site. Table 5 shows the sizing of the hybrid power plant based on a simulation in HOPP.

Table 5. Hybrid Optimization and Performance Platform Project Sizing Results

\begin{tabular}{|l|c|c|}
\hline Hybrid Plant Component Sizing & \multicolumn{2}{|c|}{ Critical Load Factor } \\
& $\mathbf{0 . 9}$ & $\mathbf{1 . 0}$ \\
\hline Wind Capacity (MW) & 21.96 & 16.89 \\
Solar Capacity (MW) & 28.04 & 33.11 \\
Storage Size (MW) & 12.35 & 18.09 \\
Storage Size (MWh) & 821.40 & 1384.76 \\
\hline
\end{tabular}

When assuming a critical load factor of 0.9 , the total solar capacity is sized at approximately $28 \mathrm{MW}$, the total wind capacity is sized at approximately $22 \mathrm{MW}$, and the total storage capacity is sized at approximately $12 \mathrm{MW}$. Figure $5 \mathrm{a}$ shows how wind and solar generation complement each other over the course of a representative day at this site, with solar ramping up to peak at midday at just under $10 \mathrm{MW}$ (orange curve), and wind generation following an inverse trend (blue curve). Wind production is highest at night (just over $8 \mathrm{MW}$ ) when there is no solar production. Then, as solar production begins to increase in the morning hours, wind production decreases to a midday low. The aggregate generated power between these two sources (pink curve) is smoother than either the solar or wind generation alone, with sustained production at night between 8 and $10 \mathrm{MW}$, a daytime peak around $12 \mathrm{MW}$, and an evening minimum at about 17:00, as wind production increases and solar production decreases. Stored power smooths this power generation more, providing 2-4 MW throughout the day (brown curve). Stored power is used mostly at night, beginning in the evening hours during the solar and wind aggregate minimum power production at 17:00. The green curve represents the aggregate power supplied by wind, solar, and storage resources, which is consistently between 12 and 16 MW, with peak supply hours coinciding with peak solar production hours. Because a constant demand is assumed to be $10 \mathrm{MW}$, both wind and solar must be curtailed throughout the day. Those curtailments, along with the amount of load not met, are shown in Figure 5b. Solar power production, unsurprisingly, is increasingly curtailed during peak production hours. Wind power production is curtailed by $2.5-4 \mathrm{MW}$ per hour. With this plant sizing, there is also a consistent energy shortfall of $250-750 \mathrm{~kW}$ throughout the day, as was planned for the 0.9 critical load factor.

When assuming a critical load factor of 1.0, the total solar capacity is sized for approximately $33 \mathrm{MW}$, the total wind capacity is sized for approximately $17 \mathrm{MW}$, and the total storage capacity is sized for approximately $18 \mathrm{MW}$. Figure 6 shows the supplied power from solar and wind generation and from storage assets over the course of a representative day. Because demand is again assumed to be constant at $10 \mathrm{MW}$, the generation and storage profiles are similar to those of Figure 5, with only a $1 \mathrm{MW}$ difference in estimated constant demand throughout the day. With a critical load factor of 1.0, the optimal hybrid power plant sizing shifts to provide more generated power through solar rather than wind assets, presumably driven by cost. This shift results in solar power production peaking at near $11 \mathrm{MW}$ during the day rather than at less than $10 \mathrm{MW}$; however, solar curtailment is reduced by nearly $1 \mathrm{MW}$ at peak production. Wind power production also decreases, with nighttime wind production at $7 \mathrm{MW}$ rather than 9 MW, and curtailment reduced to 1-2.75 MW per hour (rather than 2.5-4 MW per hour in the 0.9 critical load factor case). Storage is similar between the two critical load factor cases, with approximately $4 \mathrm{MW}$ per hour supplied during the night and $2 \mathrm{MW}$ per hour supplied during the day.

Both critical load factor cases show the benefit of hybridization in a distribution-level system. Solar power generation alone would not meet the demand in a constant load scenario, as no solar power is generated at night, and the storage capacity required to ensure demand is met is large and expensive, even for the $10 \mathrm{MW}$ load of this microgrid. Hybridizing a microgrid by adding wind power generation enables smoother power output and decreased storage 


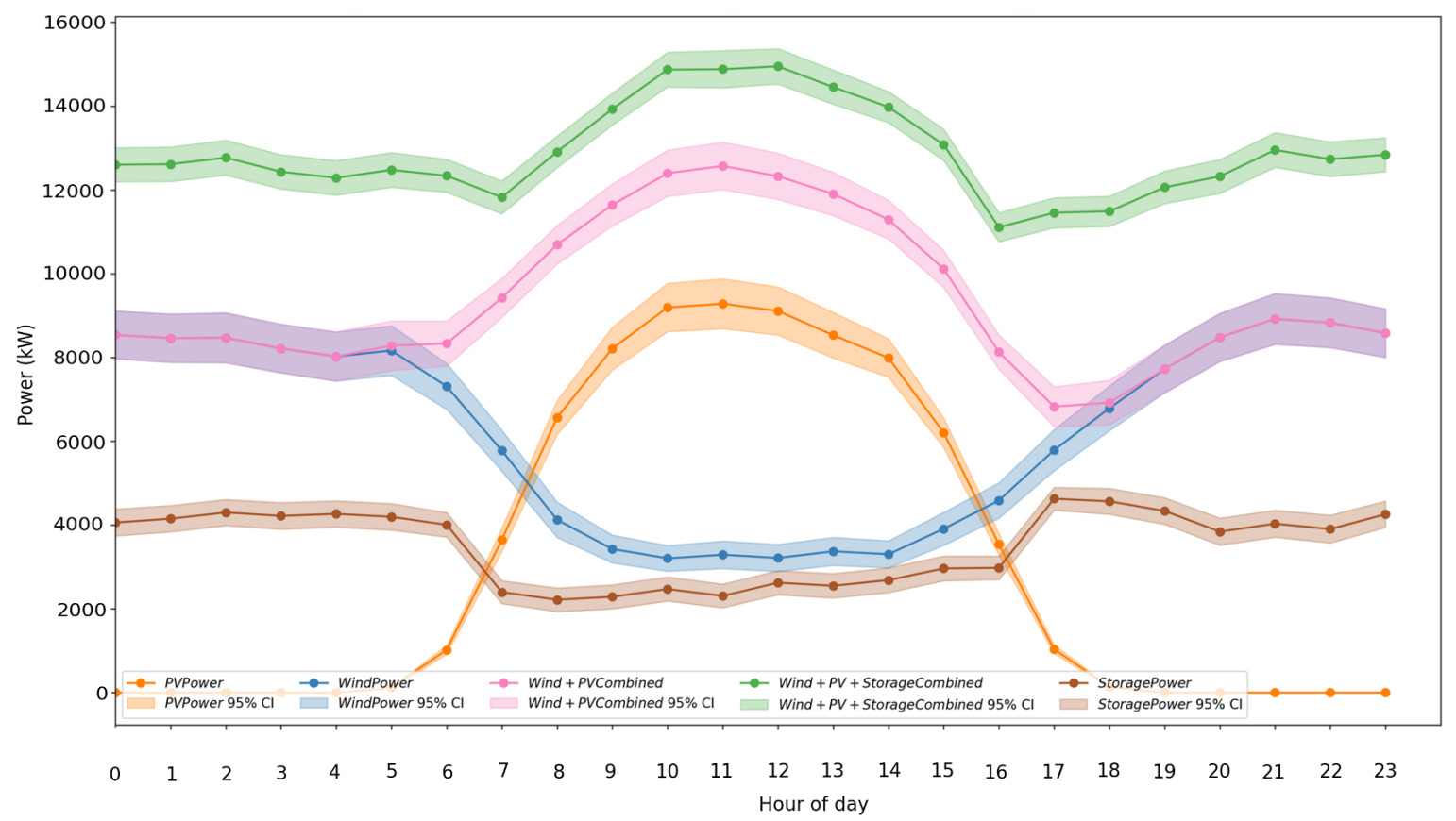

(a) Generation and storage profiles for the 0.9 critical load factor $(\mathrm{Cl}=$ confidence interval)

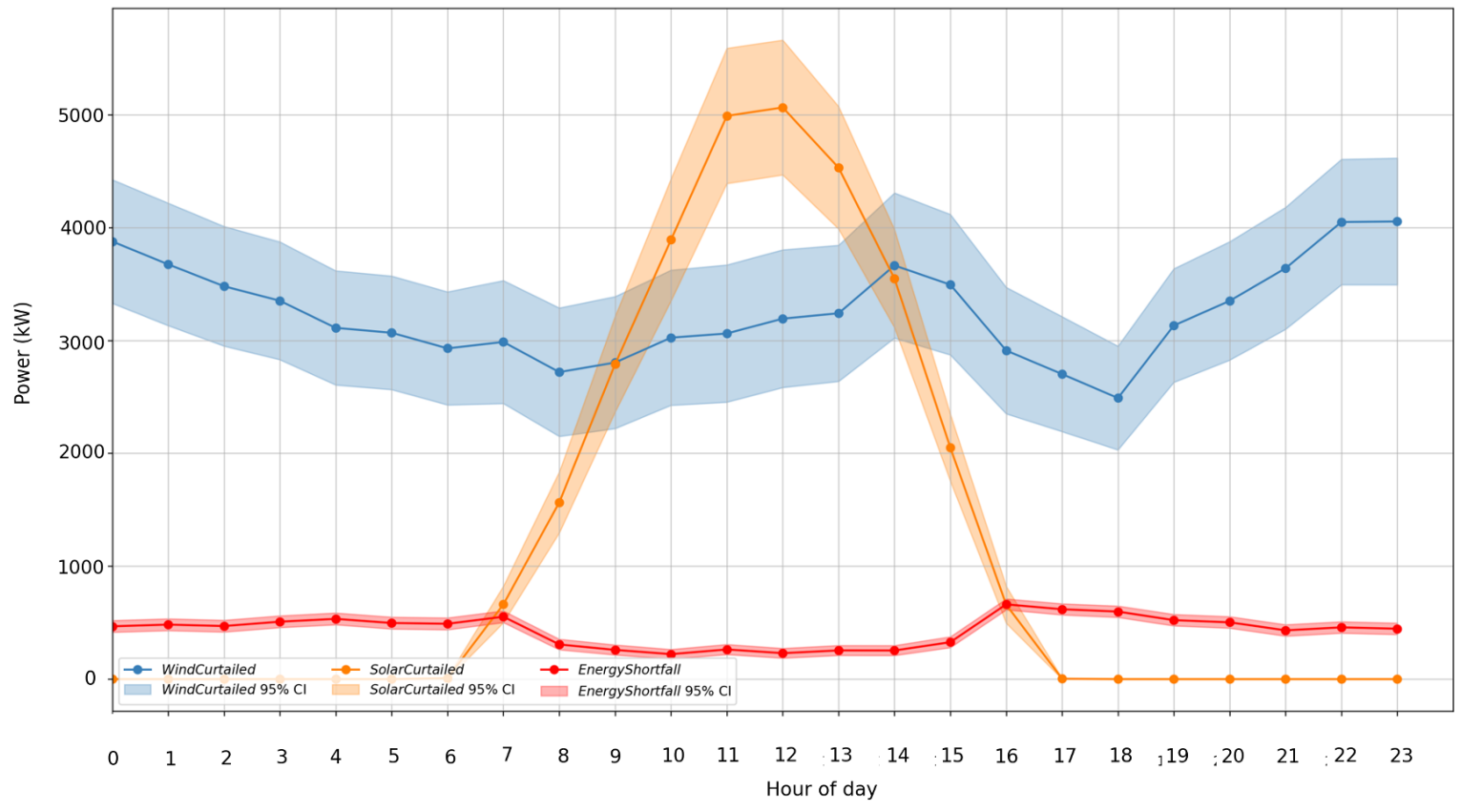

(b) Profiles of wind and solar curtailment and energy shortfall

Figure 5. Hybrid plant performance for Naval Support Activity Mid-South given a 0.9 critical load factor 


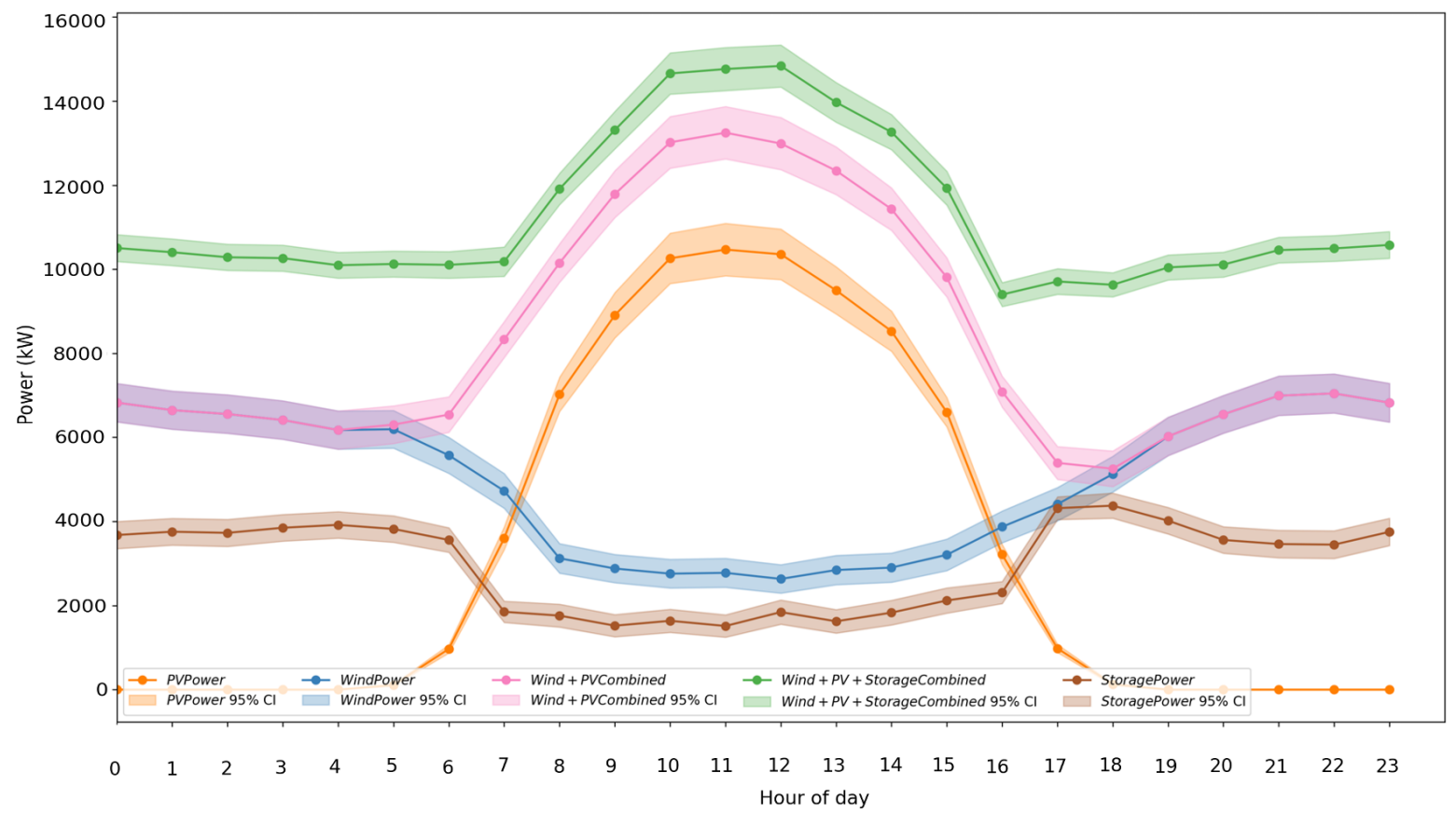

(a) Generation and storage profiles for the 1.0 critical load factor

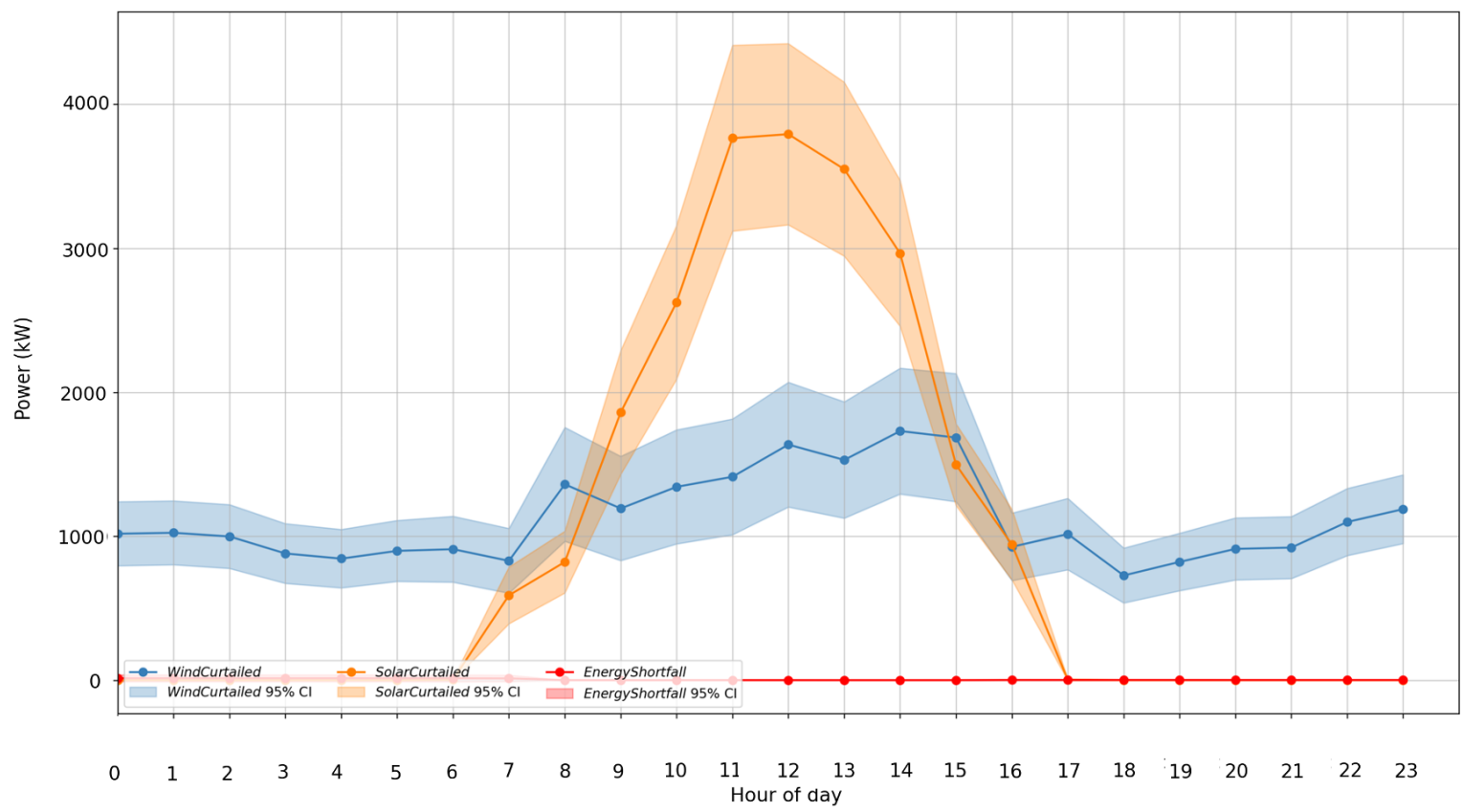

(b) Profiles for wind and solar curtailment and energy shortfall

Figure 6. Hybrid plant performance for Naval Support Activity Mid-South given a 1.0 critical load factor 
capacity requirements. Further, in a disruptive event like a cloudy day, the system generates enough power to meet demand (shown by the curtailment profiles), especially when wind constitutes a greater share of base generation.

Some of the metrics described in Section 2 are relevant to this particular system. First, because we assume this hybrid plant is functionally a microgrid, it is completely autonomous. That is, there is no selling or buying of electricity to or from the larger grid. We also assume that when we optimize the hybrid plant for a critical load factor of 0.9, we meet any energy shortfall with diesel generation. We can therefore quantify diesel generation, which is a direct artifact of the critical factor load setting. Because of this, "load not served" will always be $0 \mathrm{MW}$. In Figure 5b, the energy shortfall is approximately $250 \mathrm{~kW}$ ( $0.025 \%$ of load) during daylight hours, or from 08:00 to 15:00. The energy shortfall increases during nighttime to approximately $500 \mathrm{~kW}$ ( $0.05 \%$ of load) between 16:00 and 07:00 the next morning.

Second, because of our assumption of an isolated microgrid, the ability to quantify usage efficiency is somewhat limited. Metrics that take into account the import and export of energy relative to local use are not relevant, but energy use relative to curtailment can provide a proxy to the energy efficiency of the system. This metric enables one to compare the system sizing and efficiency and becomes particularly relevant in systems designed to supply load during long-duration outages or capacity loss, in which the system might be overbuilt to accommodate such an event. Figure $5 \mathrm{~b}$ depicts the curtailment of both solar and wind assets in the reference system designed for a critical load factor of 0.9. In this system, approximately 72 megawatt-hours (MWh) of wind energy generation and $30 \mathrm{MWh}$ of solar energy generation are curtailed, or approximately $30 \%$ of the energy produced is curtailed. In the reference system designed for a critical load factor of 1.0 (Figure 6b), approximately $19 \mathrm{MWh}$ of wind energy generation and $46.5 \mathrm{MWh}$ of solar energy generation is curtailed, resulting in a sum curtailment of $16 \%$ of the total energy generation.

Finally, sustainable ride-through is an important statistic that should be quantified for both isolated and connected distributed grid systems. Sustainable ride-through depends not only on detailed local demand data but also on local hazard and outage data. In most studies reviewed, ride-through statistics were offered in reference to a single outage scenario. Although this approach enables the design of distributed renewable energy systems with more resiliency than systems in which an outage event has not been considered, it is limited. Ongoing research at NREL uses a Monte Carlo analysis with varying outage duration and frequency to quantify load not served in transmission systems. This type of approach enables stakeholders to measure system resilience in a more robust way and to incorporate uncertainty (via probabilistic outage scenarios) into their decision-making (e.g., they can answer the question, "How does the probability of outage frequency and duration impact the load not served?"). Although we do not quantify sustainable ride-through in this particular reference system because of a lack of outage data, future work will define probabilistic outage scenarios, quantify the sustainable ride-through required for a system to endure these scenarios, and leverage this information as a basis for resilient hybrid system design. 


\section{Conclusions and Future Work}

In this study, we aimed to identify regions of the United States that have adequate wind and solar resources, as well as complementarity of those resources, to support hybrid plant development. Daily- and hourly-averaged complementarity analyses show that areas in the Great Plains, Midwest, Southeast, and nonmountainous Northeast are all regions in which there is high complementarity. Regions with complex terrain (Alaska and western regions of CONUS) could also have areas of high complementarity but require local analysis because complementarity is so spatially and temporally variable. Furthermore, areas in the Northeast and Southeast require more local analysis because although complementarity is high, the abundance of one or more resources might be low, limiting the ability to provide resilience value in disruptive events. To exemplify this local analysis, we used the HOPP tool to optimally size a hybrid power plant for a microgrid near Memphis, Tennessee. Results for critical load factors of 0.9 and 1.0 indicate that solar power generation alone would not meet the demand in a constant load scenario, but pairing solar power generation with wind power generation and storage capacity could provide smoother power output and would better meet local demand, with extra capacity available.

Although this work provides a national analysis to identify hybrid power plant opportunities and uses a reference system to demonstrate the benefit that hybrid plants could provide to distribution-level power systems, it is only the first step in understanding how to fully leverage hybrid power plants in U.S. power systems to provide resilience value. To address this aim, future work would require 1) consistent resource data, 2) more detailed local analysis, and 3) consideration of resilience-specific complementarity metrics.

As discussed in Section 4.1, the data used for Alaska and CONUS were not consistent because of the availability of wind and solar resource data. Current efforts to extend WIND Toolkit and the National Solar Radiation Database to include northern climates are underway but were not completed at the time of this study. It is critical to generate consistent data and validate that data via ground measurements to correctly estimate available resources and technically available resources. Arctic climates have many special considerations for the design of renewable energy systems, and understanding the availability of renewable resources is foundational in designing solutions for these regions. HOPP, which relies on data from the WIND Toolkit and the National Solar Radiation Database, can be amended when new wind and solar resource data become available to take into account the Arctic climate considerations needed to estimate the technical generation ability of renewable energy generation assets. Further, by extending the analysis to include multiple years, interannual variability can be considered, which will ultimately reduce resource uncertainty.

With respect to the need for more detailed local analysis, our national complementarity analysis showed that complementarity is spatially and temporally variable, especially in complex terrain. Although finer spatial resolution might benefit the complementarity analysis in complex terrain, it prompts the question, How fine a resolution is enough? This study focuses on distribution-level power systems, which are at a local community or county scale. Although this work shows opportunity for hybrid plants in the United States from a resource perspective, specific, local data are needed to understand the ability of a distribution-level hybrid plant to meet the resilience objectives of a local power system given available resources, demand, and hazards. With local demand and hazard data, for instance, the hybrid power plant designed for the reference system in this study could be sized to meet actual demand during both nominal and disruptive conditions instead of an assumed constant load.

These two areas of future work lead to a final future work suggestion. First, by reducing uncertainty in local resources by ensuring consistent, multiyear resource data and analyzing those data at the local level alongside local demand and hazard data, we would be able to estimate power system resilience through reliability-based hybrid metrics and resilience frameworks, as discussed in Section 2. Second, complementarity analysis has thus far used metrics that estimate the hybrid benefit to renewable energy generation reliability. If we considered low-probability events with these metrics - thereby evaluating the resilience benefit rather than reliability - and integrated them with power system resilience frameworks, we would be able to estimate the resilience benefit that distribution-level hybrid power plants could provide a specific community. 


\section{References}

Aza-Gnandji, M., F. X. Fifatin, A. H. J. Hounnou, F. Dubas, D. Chamagne, C. Espanet, and A. Vianou. 2018. "Complementarity between Solar and Wind Energy Potentials in Benin Republic". Advanced Engineering Forum 28 (June): 128-138. ISSN: 2234-991X. doi:10.4028/www.scientific.net/aef.28.128.

Berger, M., D. Radu, R. Fonteneau, R. Henry, M. Glavic, X. Fettweis, M. Le Du, P. Panciatici, L. Balea, and D. Ernst. 2020. "Critical time windows for renewable resource complementarity assessment". Energy 198. ISSN: 03605442. doi:10.1016/j.energy.2020.117308.

Cicilio, P., L. Swartz, B. Vaagensmith, C. Rieger, J. Gentle, T. McJunkin, and E. Cotilla-Sanchez. 2020. "Electrical grid resilience framework with uncertainty". Electric Power Systems Research 189 (March): 106801. ISSN: 03787796. doi:10.1016/j.epsr.2020.106801. https://doi.org/10.1016/j.epsr.2020.106801.

Cutler, D., D. Olis, E. Elgqvist, X. Li, N. Laws, N. DiOrio, A. Walker, and K. Anderson. 2017. Reopt: A platform for energy system integration and optimization. Tech. rep. September. Golden, CO: National Renewable Energy Laboratory. doi:10.1115/ES2014-6570.

Dos Anjos, P. S., A. S. Alves Da Silva, B. Stošić, and T. Stošić. 2015. "Long-term correlations and cross-correlations in wind speed and solar radiation temporal series from Fernando de Noronha Island, Brazil". Physica A: Statistical Mechanics and its Applications 424:90-96. ISSN: 03784371. doi:10.1016/j.physa.2015.01.003. http://dx.doi.org/ 10.1016/j.physa.2015.01.003.

Draxl, C., A. Clifton, B. M. Hodge, and J. McCaa. 2015. "The Wind Integration National Dataset (WIND) Toolkit". Applied Energy 151:355-366. ISSN: 03062619. doi:10.1016/j.apenergy.2015.03.121. http://dx.doi.org/10.1016/j. apenergy.2015.03.121.

Gburcik, P., V. Gburcik, M. Gavrilov, V. Srdanovic, and S. Mastilovic. 2006. "Complementary regimes of solar and wind energy in Serbia". Geographica Pannonica, no. 10: 22-25. ISSN: 0354-8724. doi:10.5937/geopan0610022g.

Gorman, W., A. Mills, M. Bolinger, R. Wiser, N. G. Singhal, E. Ela, and E. O'Shaughnessy. 2020. "Motivations and options for deploying hybrid generator-plus-battery projects within the bulk power system". Electricity Journal 33 (5): 106739. ISSN: 10406190. doi:10.1016/j.tej.2020.106739. https://doi.org/10.1016/j.tej.2020.106739.

Jurasz, J., F. A. Canales, A. Kies, M. Guezgouz, and A. Beluco. 2020. "A review on the complementarity of renewable energy sources: Concept, metrics, application and future research directions". Solar Energy 195 (April 2019): 703-724. ISSN: 0038092X. doi:10.1016/j.solener.2019.11.087. arXiv: 1904.01667. https://doi.org/10.1016/j. solener.2019.11.087.

Jurasz, J., A. Beluco, and F. A. Canales. 2018a. "The impact of complementarity on power supply reliability of small scale hybrid energy systems". Energy 161:737-743. ISSN: 03605442. doi:10.1016/j. energy.2018.07.182. https://doi.org/10.1016/j.energy.2018.07.182.

- . 2018b. "The impact of complementarity on power supply reliability of small scale hybrid energy systems". Energy 161:737-743. ISSN: 03605442. doi:10.1016/j.energy.2018.07.182. https://doi.org/10.1016/j.energy.2018. 07.182 .

Kahn, E. 1979. "The reliability of distributed wind generators". Electric Power Systems Research 2 (1): 1-14. ISSN: 03787796. doi:10.1016/0378-7796(79)90021-X.

Li, Y., V. G. Agelidis, and Y. Shrivastava. 2009. "Wind-solar resource complementarity and its combined correlation with electricity load demand". 2009 4th IEEE Conference on Industrial Electronics and Applications, ICIEA 2009: 3623-3628. doi:10.1109/ICIEA.2009.5138882.

Liu, Y., L. Xiao, H. Wang, S. Dai, and Z. Qi. 2013. "Analysis on the hourly spatiotemporal complementarities between China's solar and wind energy resources spreading in a wide area". Science China Technological Sciences 56 (3): 683-692. ISSN: 16747321. doi:10.1007/s11431-012-5105-1.

Marcos, J., L. Marroyo, E. Lorenzo, and M. García. 2012. "Smoothing of PV power fluctuations by geographical dispersion". Progress in Photovoltaics: Research and Applications 20 (2): 226-237. ISSN: 10627995. doi:10.1002/ pip.1127. http://doi.wiley.com/10.1002/pip.1127.

McJunkin, T. R., and C. Rieger. 2019. "Resilient control system metrics". Advances in Information Security 75:255276. ISSN: 15682633. doi:10.1007/978-3-030-18214-4_12.

Miglietta, M. M., T. Huld, and F. Monforti-Ferrario. 2016. "Local Complementarity of Wind and Solar Energy Resources over Europe: An Assessment Study from a Meteorological Perspective". Journal of Applied Meteorology and Climatology 56 (1): 217-234. ISSN: 1558-8424. doi:10.1175/jamc-d-16-0031.1. 
Murata, A., H. Yamaguchi, and K. Otani. 2009. "A method of estimating the output fluctuation of many photovoltaic power generation systems dispersed in a wide area". Electrical Engineering in Japan (English translation of Denki Gakkai Ronbunshi) 166 (4): 9-19. ISSN: 04247760. doi:10.1002/eej.20723.

Naeem, A., N. U. Hassan, C. Yuen, and S. M. Muyeen. 2019. "Maximizing the economic benefits of a grid-tied microgrid using solar-wind complementarity". Energies 12 (3): 1-22. ISSN: 19961073. doi:10.3390/en12030395.

NASA. 2021. The POWER Project. power.larc.nasa.gov/beta.

National Renewable Energy Laboratory. 2020. System Advisor Model. Version 2020.11.29 (SAM 2020.11.29). Golden, CO.

- . 2021a. 2021 Annual Technology Baseline. Golden, CO. https://atb.nrel.gov/.

- . 2021b. Hybrid Optimization and Performance Platform (HOPP). Version 1.0. https://github.com/nrel/hopp.

Nelson, J., N. G. Johnson, K. Fahy, and T. A. Hansen. 2020. "Statistical development of microgrid resilience during islanding operations". Applied Energy 279 (July): 115724. ISSN: 03062619. doi:10.1016/j.apenergy.2020.115724. https://doi.org/10.1016/j.apenergy.2020.115724.

Obama, B. 2013. Presidential Policy Directive 21. https://obamawhitehouse.archives.gov/the-press-office/2013/02/ 12/presidential-policy-directive-critical-infrastructure-security-and-resil.

Orrell, A. C., J. S. Homer, and Y Tang. 2018. "Distributed Generation Valuation and Compensation White Paper". Pacific Northwest National Laboratory, U.S. Department of Energy, no. February. https://www. districtenergy. org /HigherLogic/System/DownloadDocumentFile . ashx ? DocumentFileKey=0103ebf 1 - 2ac9 - 7285 - b49d e615368725b2\{\\&\}forceDialog $=0$.

Reilly, J. 2020. MIRACL: Microgrids, Infrastructure Resilience, and Advanced Controls Launchpad. Tech. rep. Deparment of Energy. https://www.nrel.gov/wind/miracl.html $\{\backslash \#\}$ controls.

Reiman, A. P., J. S. Homer, B. Bhattarai, and A. C. Orrell. 2020. "Quantifying technical diversity benefits of wind as a distributed energy resource". 2020 IEEE Power and Energy Society Innovative Smart Grid Technologies Conference, ISGT 2020. doi:10.1109/ISGT45199.2020.9087665.

Ren, G., J. Wan, J. Liu, and D. Yu. 2019. "Spatial and temporal assessments of complementarity for renewable energy resources in China". Energy 177:262-275. ISSN: 03605442. doi:10.1016/j.energy.2019.04.023. https: //doi.org/10.1016/j.energy.2019.04.023.

Schmidt, J., R. Cancella, and A. O. Pereira. 2016. "An optimal mix of solar PV, wind and hydro power for a lowcarbon electricity supply in Brazil". Renewable Energy 85 (2016): 137-147. ISSN: 18790682. doi:10.1016/j. renene.2015.06.010. http://dx.doi.org/10.1016/j.renene.2015.06.010.

Sengupta, M., Y. Xie, A. Lopez, A. Habte, G. Maclaurin, and J. Shelby. 2018. "The National Solar Radiation Data Base (NSRDB)". Renewable and Sustainable Energy Reviews 89 (January 2018): 51-60. ISSN: 18790690. doi:10. 1016/j.rser.2018.03.003. https://doi.org/10.1016/j.rser.2018.03.003.

Shaner, M. R., S. J. Davis, N. S. Lewis, and K. Caldeira. 2018. "Geophysical constraints on the reliability of solar and wind power in the United States". Energy and Environmental Science 11 (4): 914-925. ISSN: 17545706. doi:10.1039/c7ee03029k.

Slusarewicz, J. H., and D. S. Cohan. 2018. "Assessing solar and wind complementarity in Texas". Renewables: Wind, Water, and Solar 5 (1). ISSN: 2198-994X. doi:10.1186/s40807-018-0054-3. https://doi.org/10.1186/s40807-0180054-3.

Sterl, S., S. Liersch, H. Koch, N. P. Lipzig, and W. Thiery. 2018. "A new approach for assessing synergies of solar and wind power: Implications for West Africa". Environmental Research Letters 13 (9). ISSN: 17489326. doi:10. 1088/1748-9326/aad8f6.

Tarroja, B., F. Mueller, and S. Samuelsen. 2013. "Solar power variability and spatial diversification: implications from an electric grid load balancing perspective". International Journal of Energy Research 37 (9): 1002-1016. ISSN: 0363907X. doi:10.1002/er.2903. arXiv: arXiv:1011.1669v3. http://doi.wiley.com/10.1002/er.2903.

Tierney, K., and M. Bruneau. 2007. "A Key to Disaster Loss Reduction". TR News: 14-18. ISSN: 07386826. http: //onlinepubs.trb.org/onlinepubs/trnews/trnews250\{\_\}p14-17.pdf.

U.S. Department of Energy. 2017. "Modern Distribution Grid Report, Volume III: Decision Guide". III:June 28. https://gridarchitecture.pnnl.gov/media/Modern-Distribution-Grid-Volume-III.pdf\{\\%\}0Ahttps://gridarchitecture. pnnl.gov/modern-grid-distribution-project.aspx.

Vega-Sanchez, M. A., P. D. Castaneda-Jimenez, R. Pena-Gallardo, A. Ruiz-Alonso, J. A. Morales-Saldana, and E. R. Palacios-Hernandez. 2017. "Evaluation of complementarity of wind and solar energy resources over Mexico using an image processing approach". 2017 IEEE International Autumn Meeting on Power, Electronics and Computing, ROPEC 2017 2018-Janua (Ropec): 1-5. doi:10.1109/ROPEC.2017.8261637. 
Widén, J. 2011. "Correlations between large-scale solar and wind power in a future scenario for Sweden". IEEE Transactions on Sustainable Energy 2 (2): 177-184. ISSN: 19493029. doi:10.1109/TSTE.2010.2101620.

- . 2015. "A model of spatially integrated solar irradiance variability based on logarithmic station-pair correlations". Solar Energy 122:1409-1424. ISSN: 0038092X. doi:10.1016/j.solener.2015.10.043.

$\mathrm{Xu}, \mathrm{L}$., Z. Wang, and Y. Liu. 2017. "The spatial and temporal variation features of wind-sun complementarity in China". Energy Conversion and Management 154 (June): 138-148. ISSN: 01968904. doi:10.1016/j .enconman. 2017.10.031. https://doi.org/10.1016/j.enconman.2017.10.031.

Zhang, H., Y. Cao, Y. Zhang, and V. Terzija. 2018. "Quantitative synergy assessment of regional wind-solar energy resources based on MERRA reanalysis data". Applied Energy 216 (February): 172-182. ISSN: 03062619. doi:10. 1016/j.apenergy.2018.02.094. https://doi.org/10.1016/j.apenergy.2018.02.094. 


\section{Appendix A Annual Complementarity for 2013, Contiguous United States}

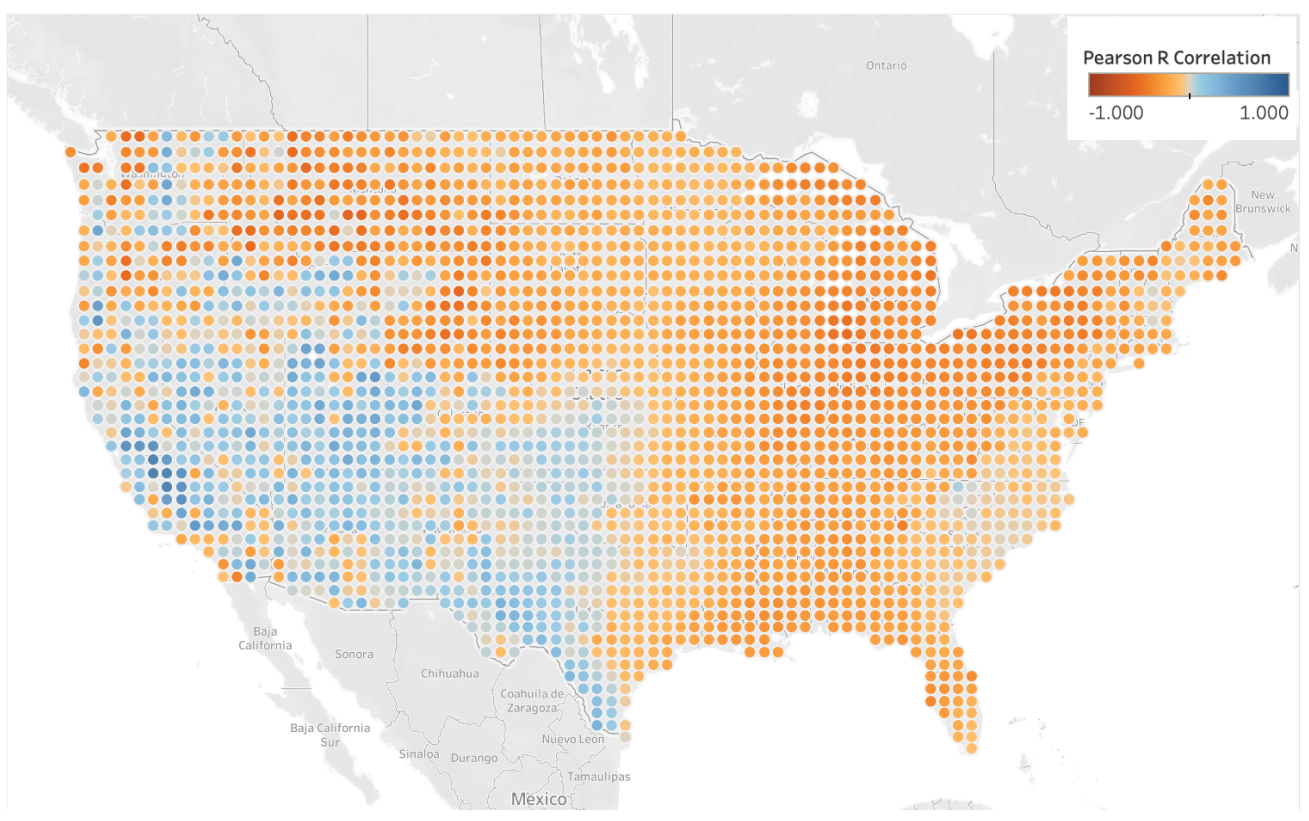

Figure Appendix A.1. Annual, daily-averaged complementarity (represented by the Pearson correlation metric) for 2013 in the contiguous United States

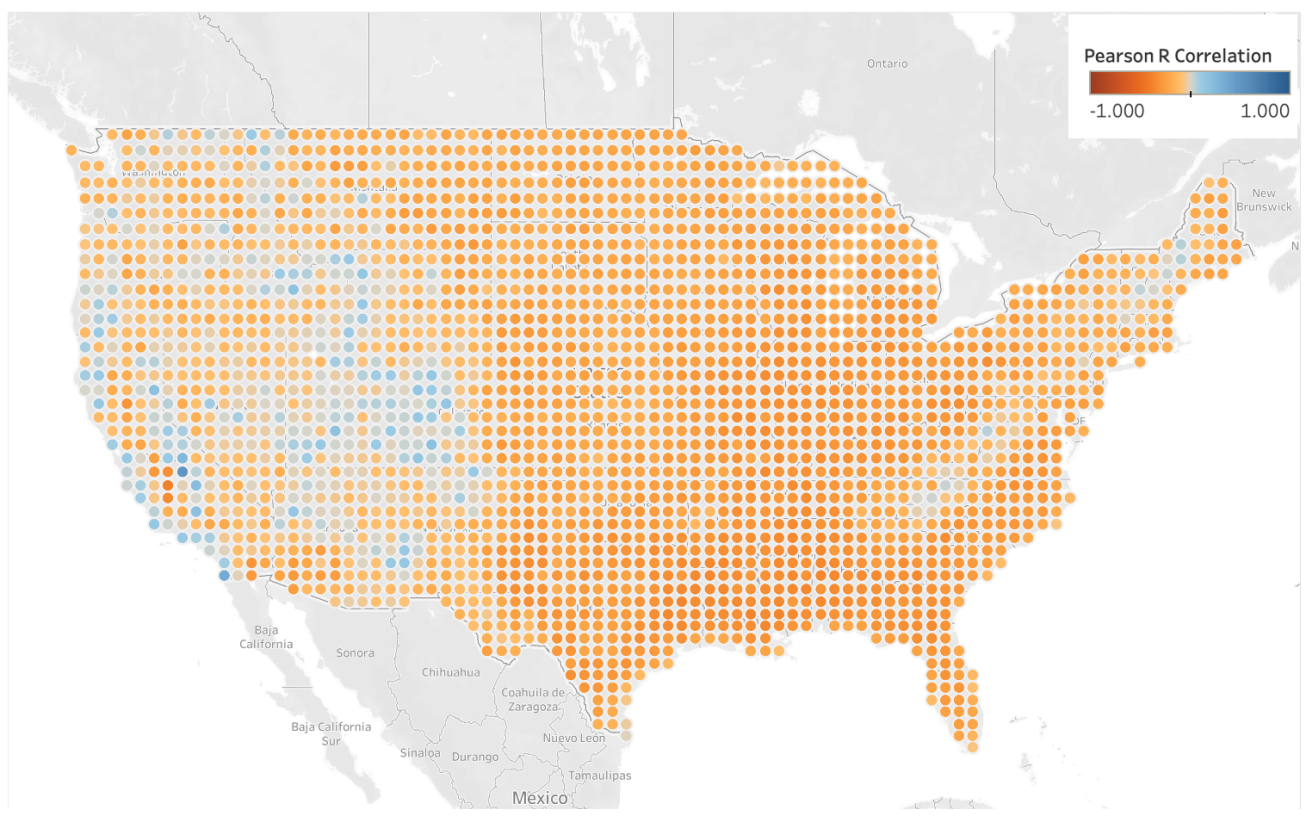

Figure Appendix A.2. Annual, hourly-averaged complementarity (represented by the Pearson correlation metric) for 2013 in the contiguous United States 


\section{Appendix B Annual Average Wind Speed and Global Horizontal Irradiance for 2013, Contiguous United States}

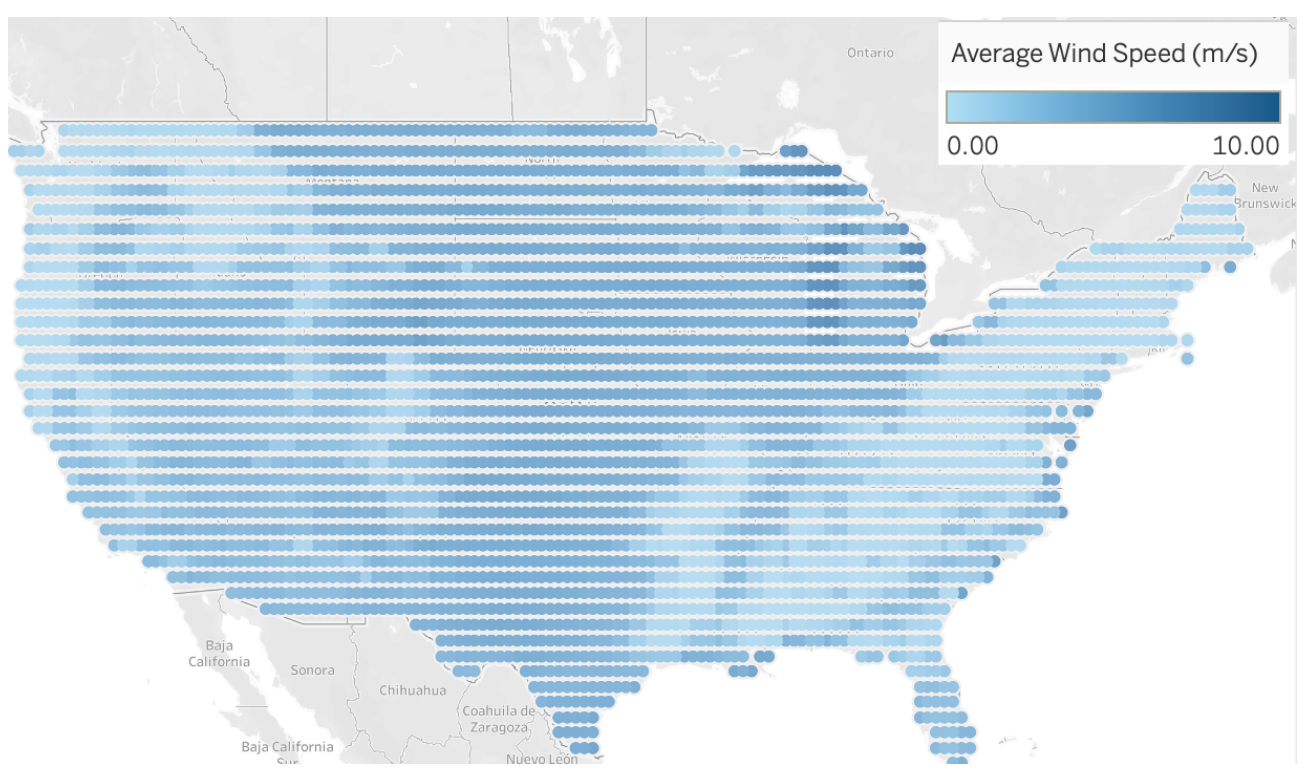

Figure Appendix B.1. Average annual wind speed in meters per second $(\mathrm{m} / \mathrm{s})$ for 2013 in the contiguous United States

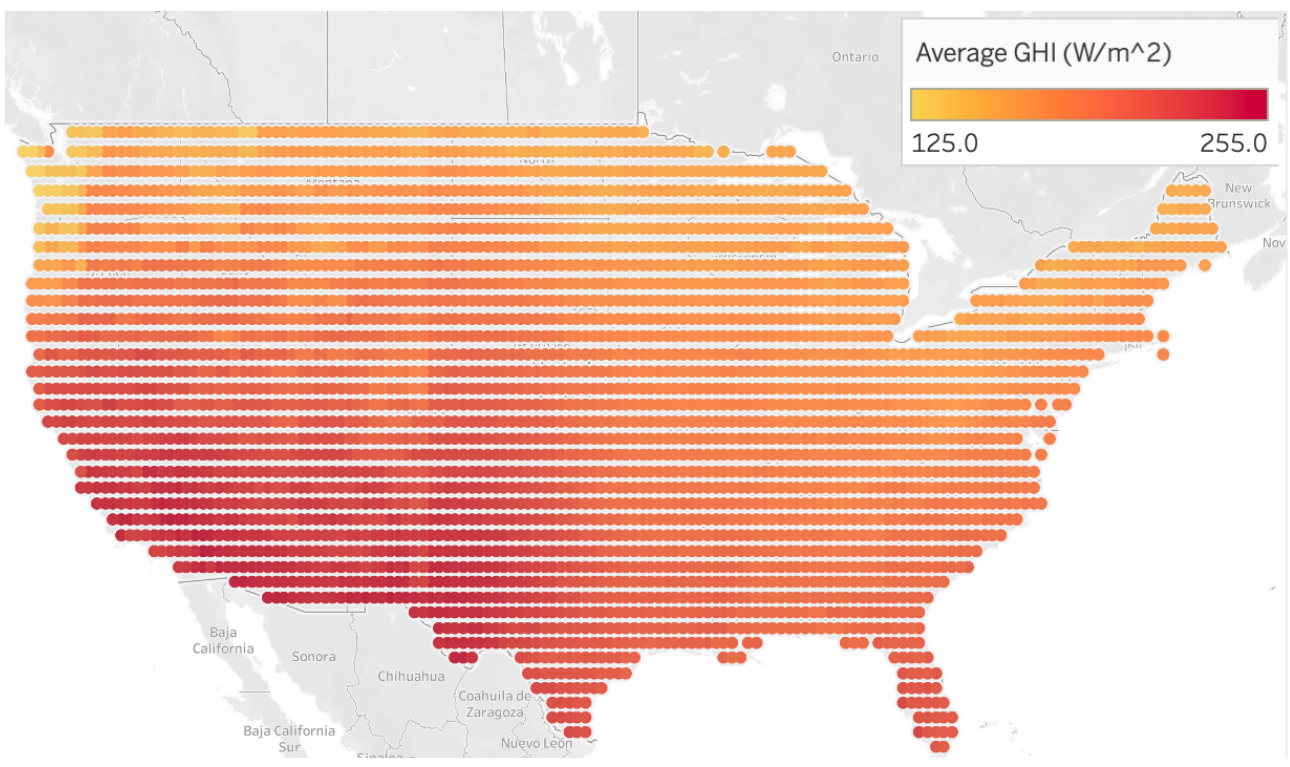

Figure Appendix B.2. Average annual global horizontal irradiance (GHI) in watts per square meter $\left(\mathrm{W} / \mathrm{m}^{2}\right)$ for 2013 in the contiguous United States 


\section{Appendix C Annual Complementarity for 2013, Hawaii}

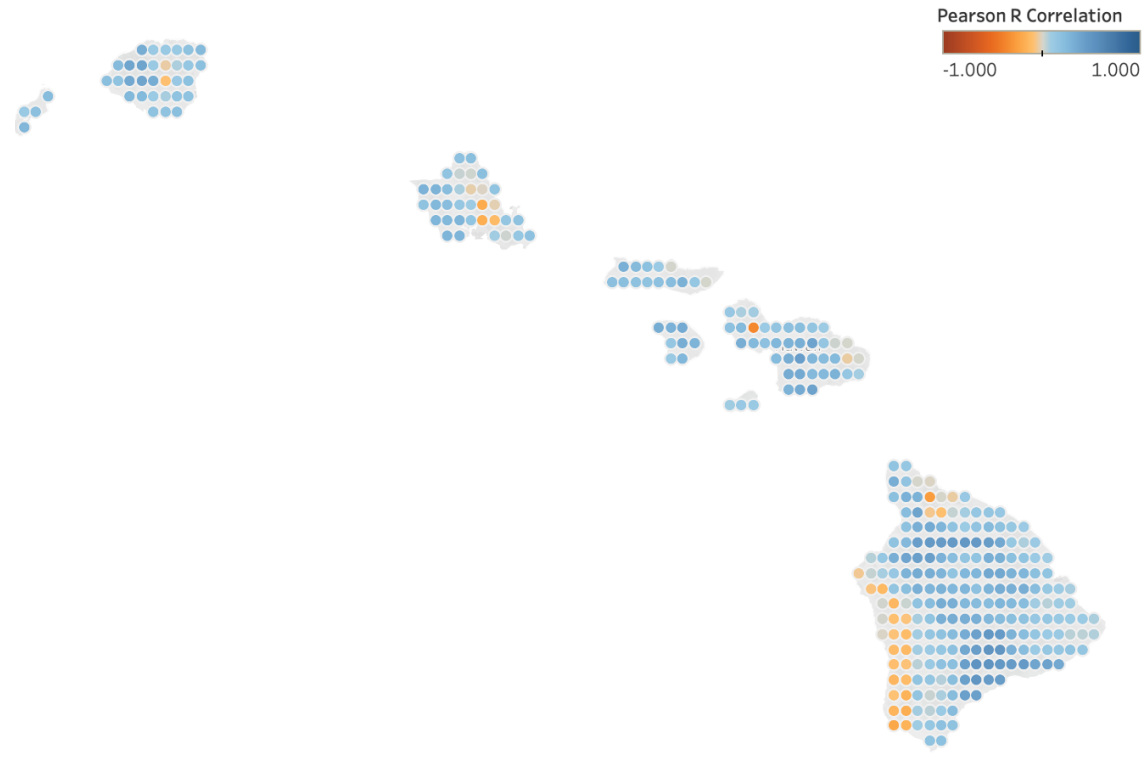

Figure Appendix C.1. Annual, daily-averaged complementarity (represented by the Pearson correlation metric) for 2013 in Hawaii

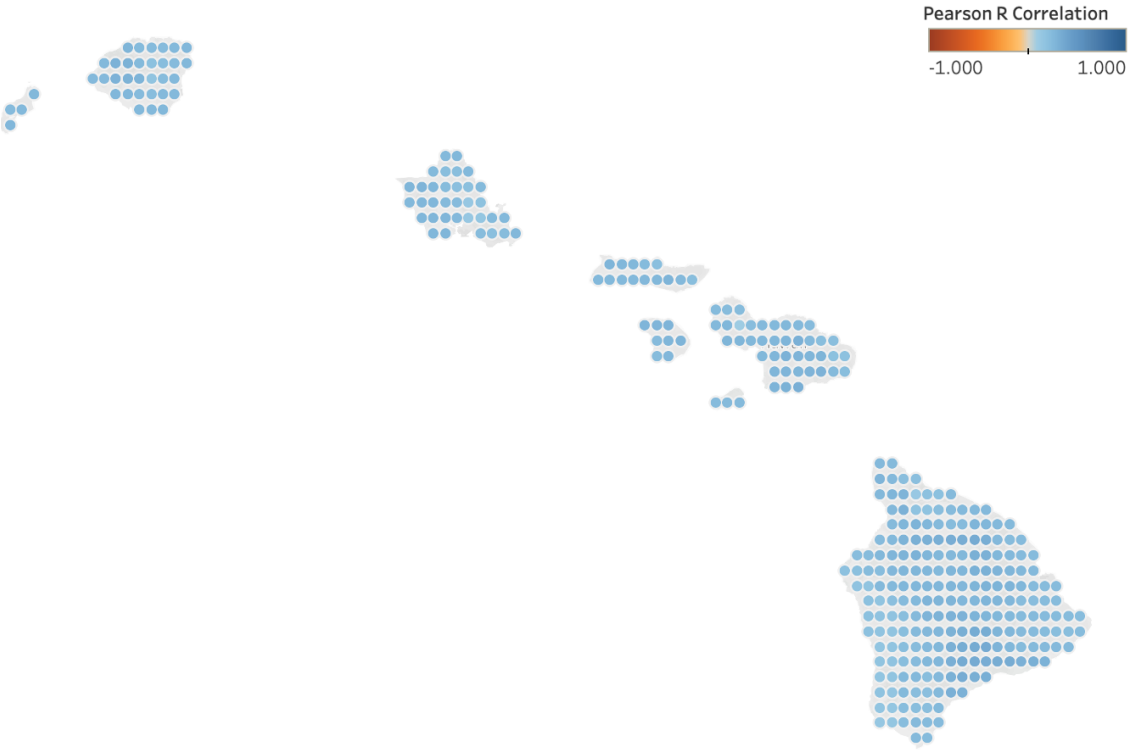

Figure Appendix C.2. Annual, hourly-averaged complementarity (represented by the Pearson correlation metric) for 2013 in Hawaii 


\section{Appendix D Annual Average Wind Speed and Global Horizontal Irradiance for 2013, Hawaii}

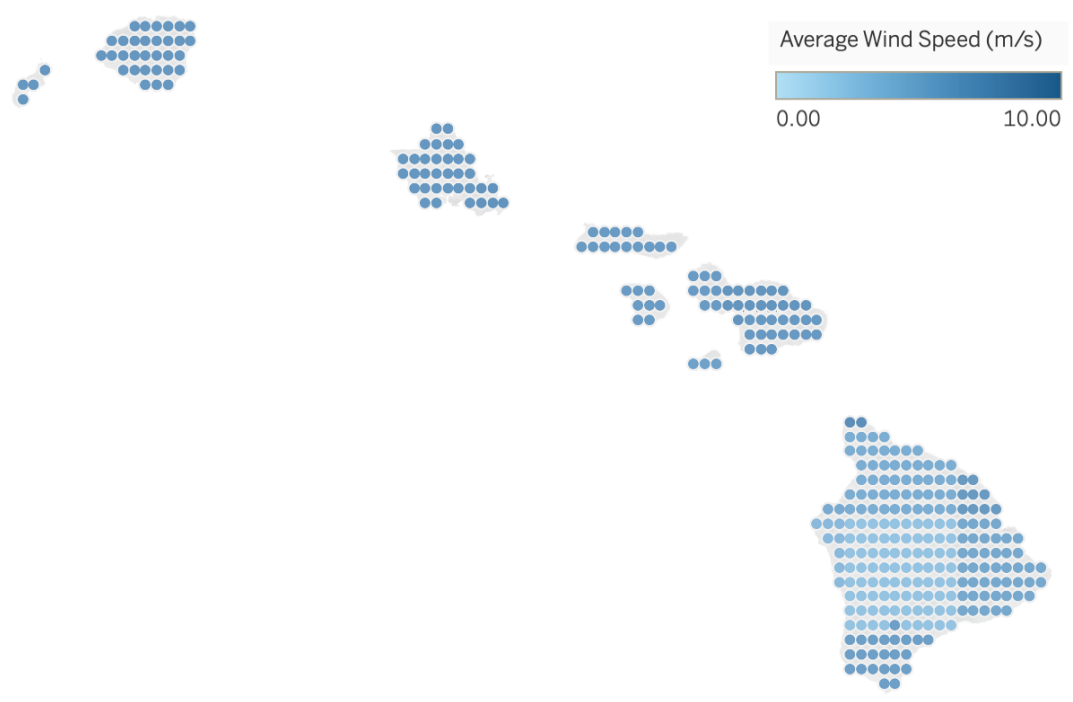

Figure Appendix D.1. Average annual wind speed (m/s) for 2013 in Hawaii

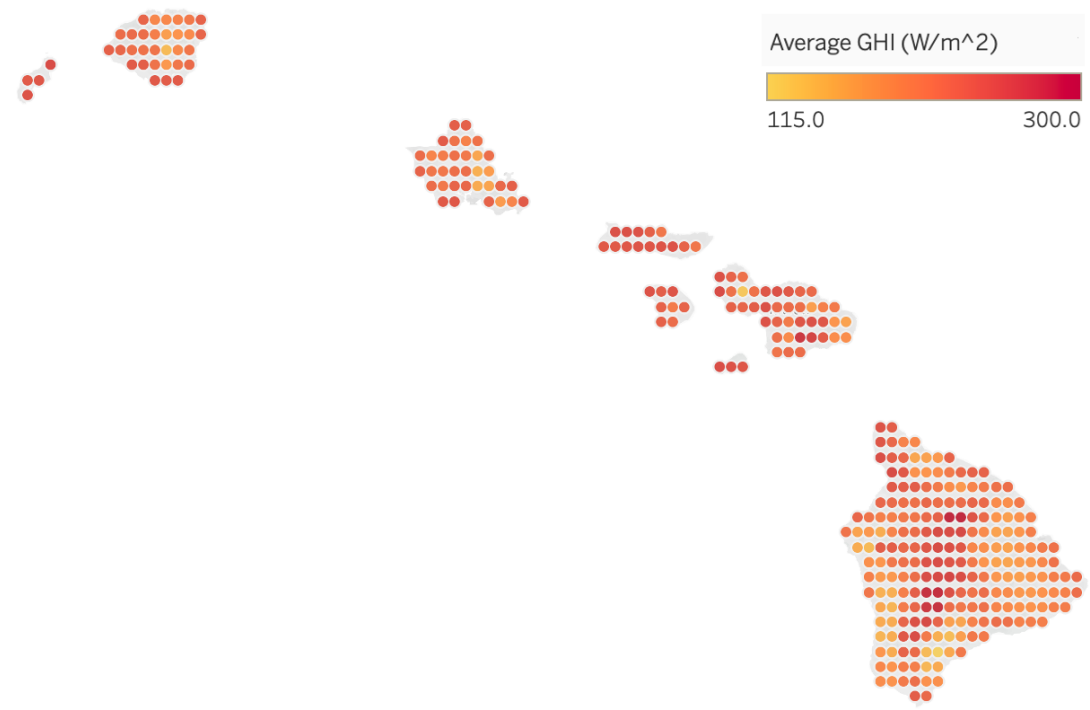

Figure Appendix D.2. Average annual global horizontal irradiance $\left(W / m^{2}\right)$ for 2013 in Hawaii 


\section{Appendix E Annual Complementarity for 2013, Alaska}

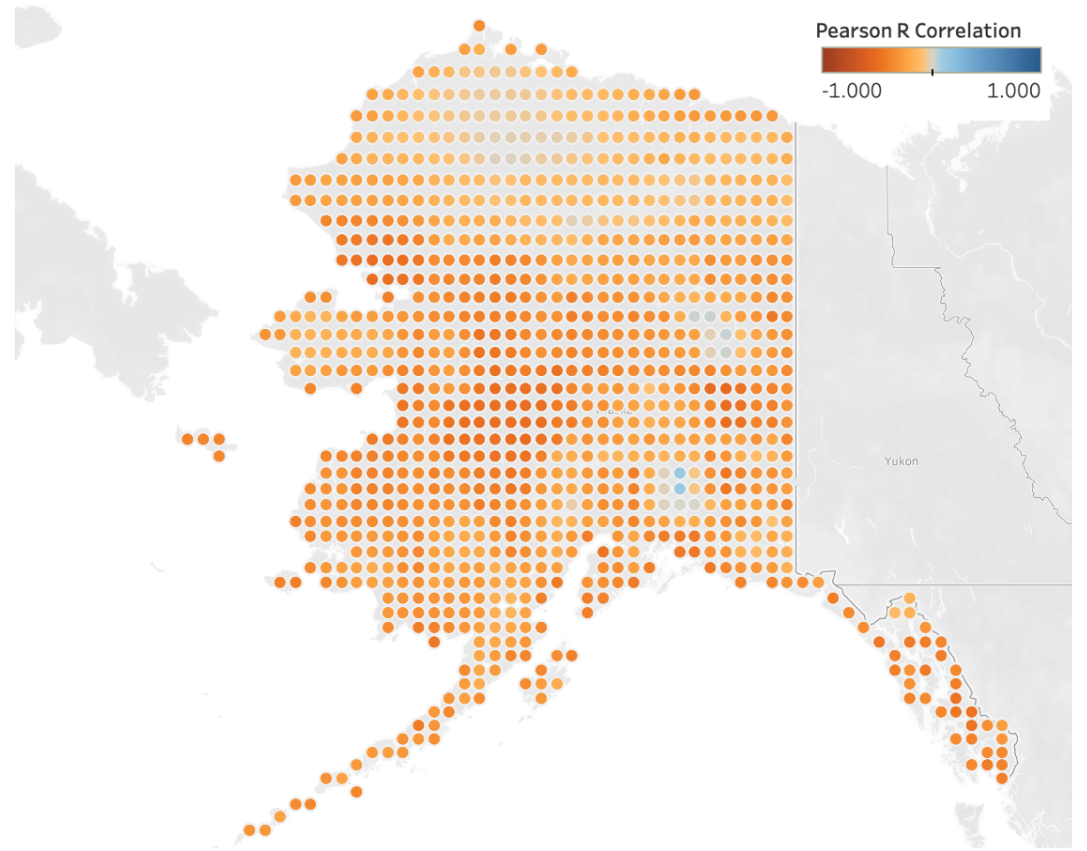

Figure Appendix E.1. Annual, daily-averaged complementarity (represented by the Pearson correlation metric) for 2013 in Alaska

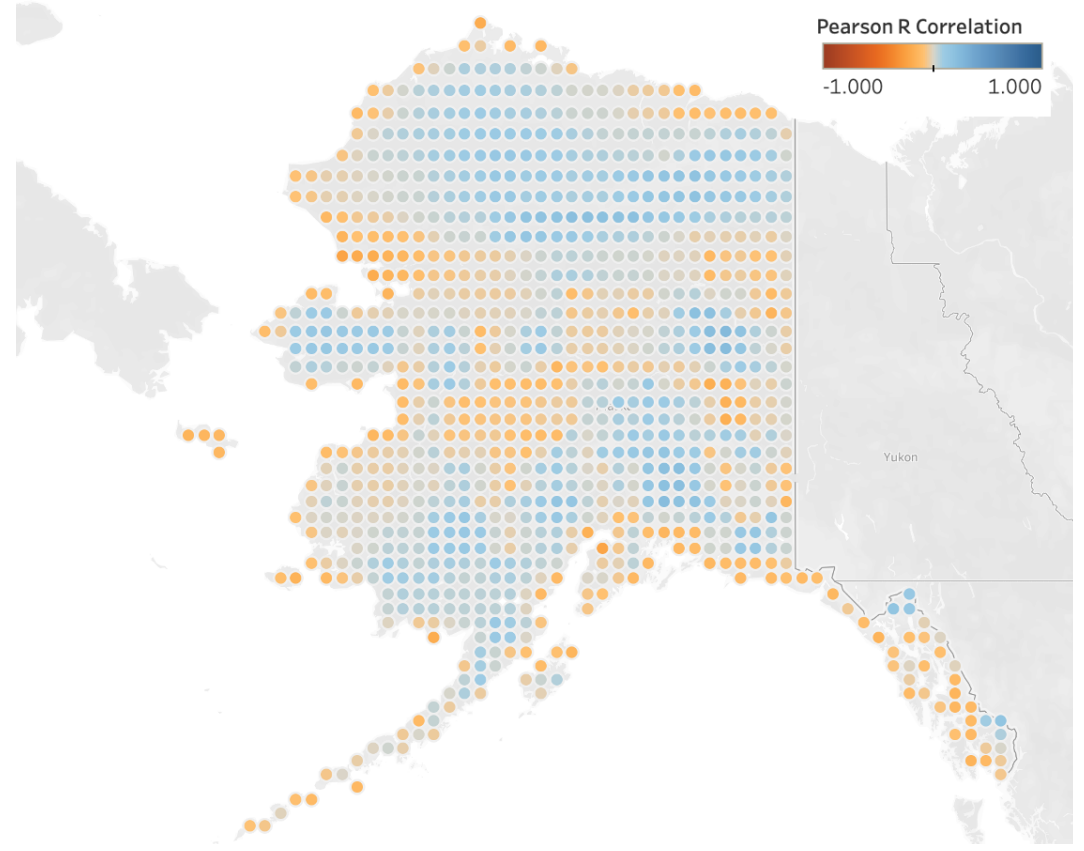

Figure Appendix E.2. Annual, hourly-averaged complementarity (represented by the Pearson correlation metric) for 2013 in Alaska 


\section{Appendix F Annual Average Wind Speed and Global Horizontal Irradiance for 2013, Alaska}

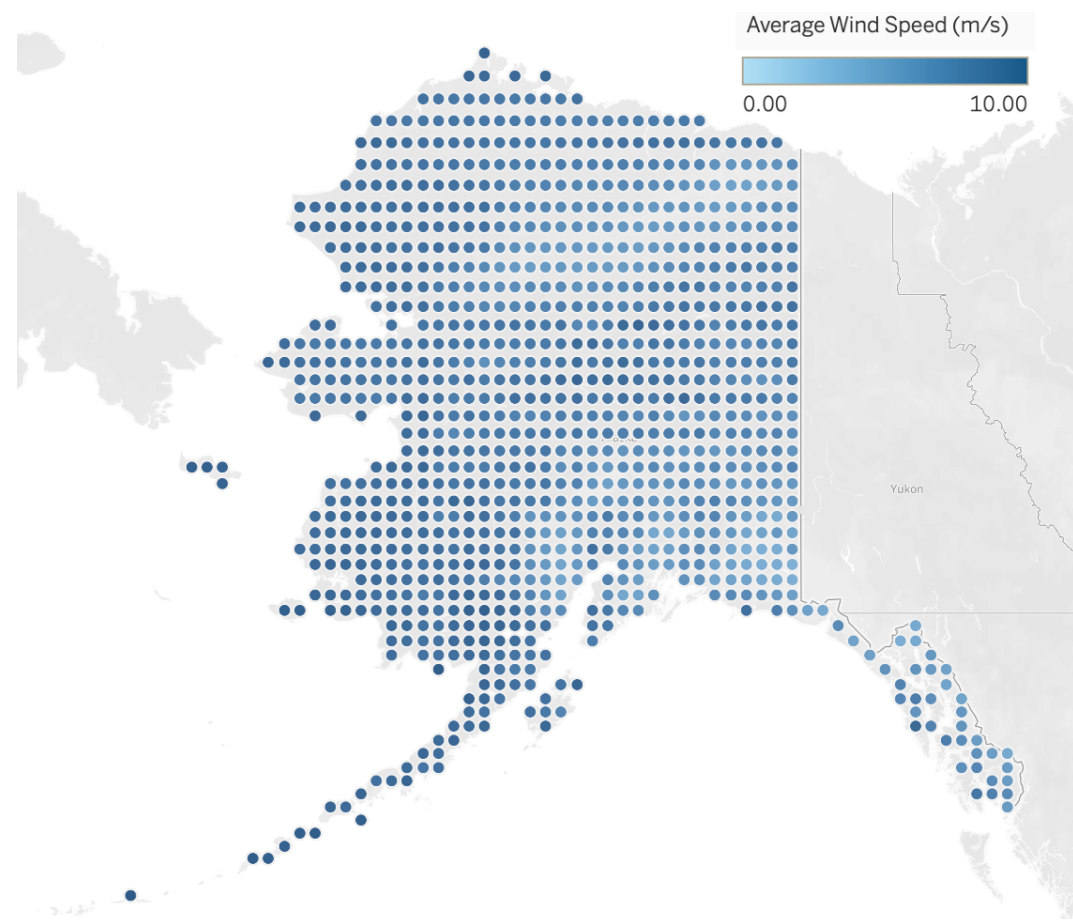

Figure Appendix F.1. Average annual wind speed (m/s) for 2013 in Alaska

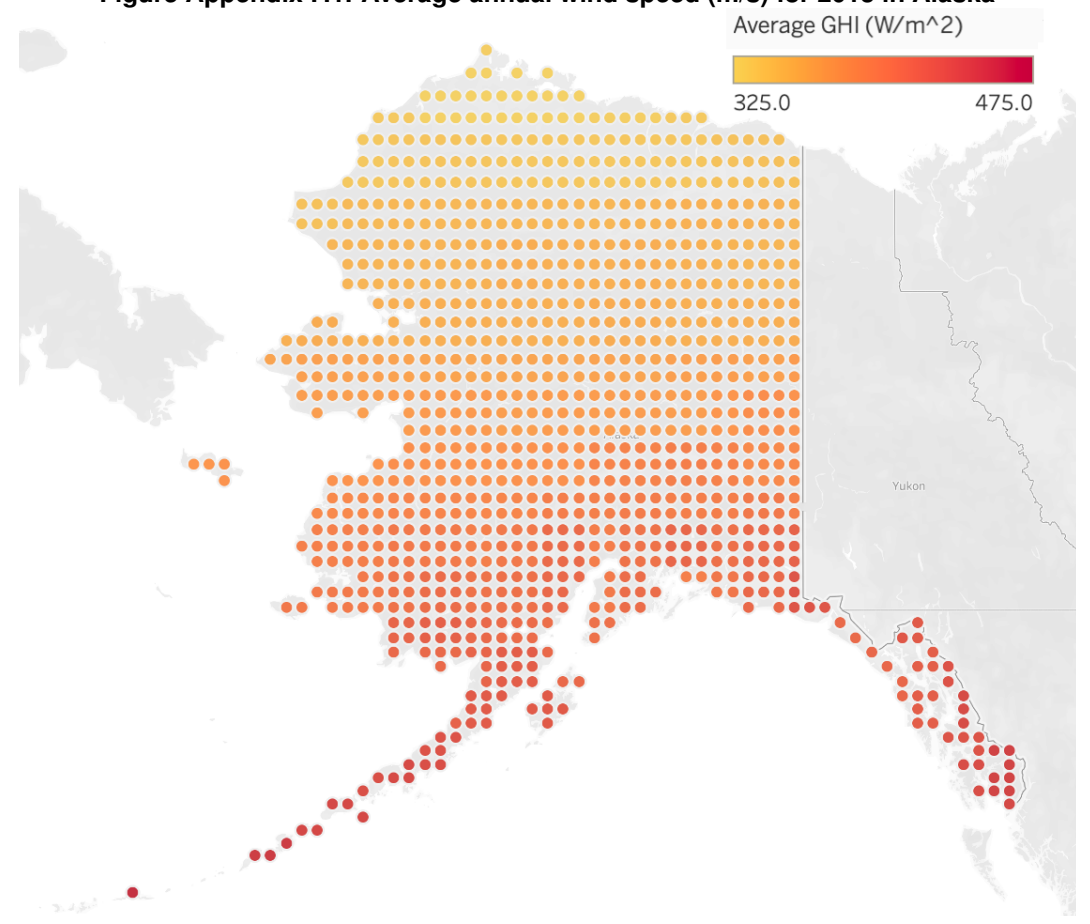

Figure Appendix F.2. Average annual global horizontal irradiance $\left(W / m^{2}\right)$ for 2013 in Alaska 


\section{Appendix G Complementarity per Month, Contiguous United}

\section{States}

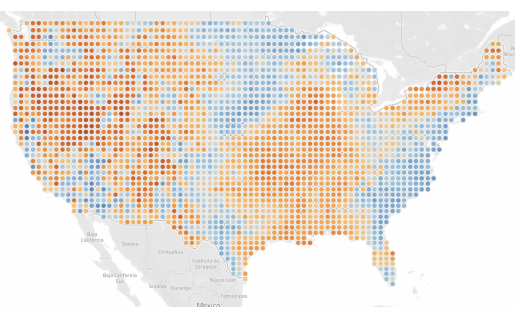

(a) January

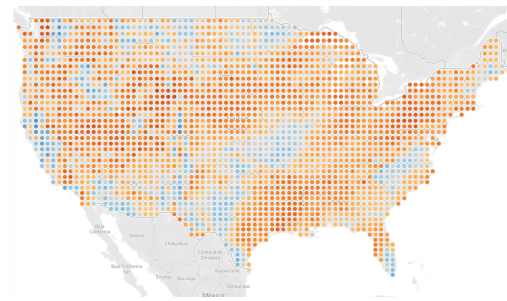

(d) April

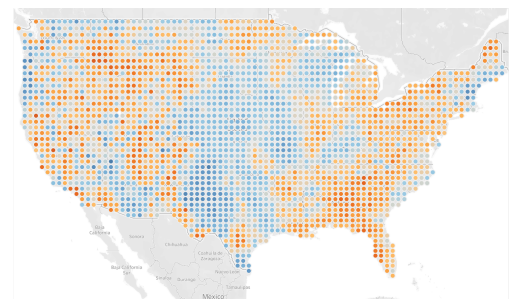

(g) July

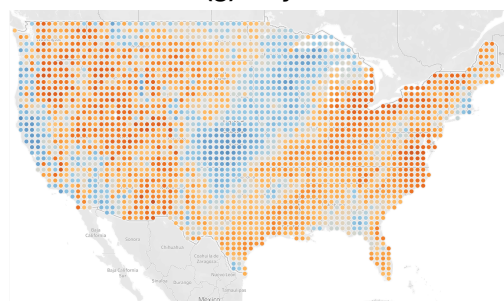

(j) October

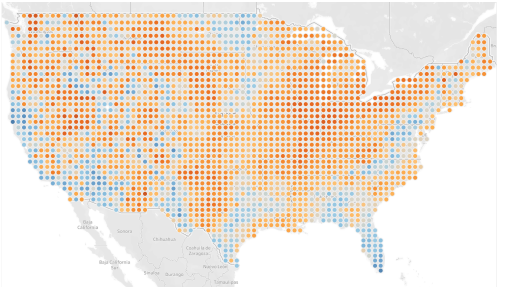

(b) February

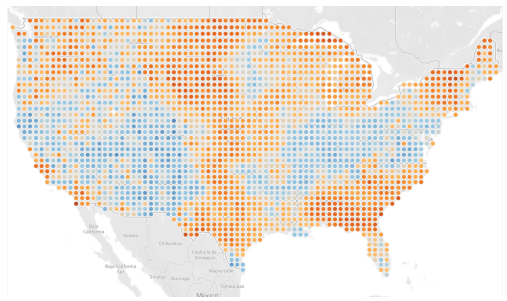

(e) May

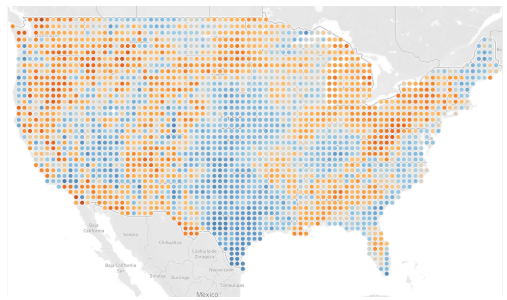

(h) August

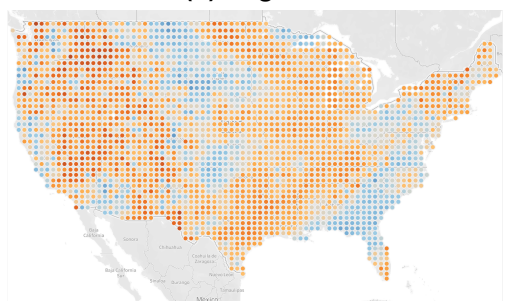

(k) November

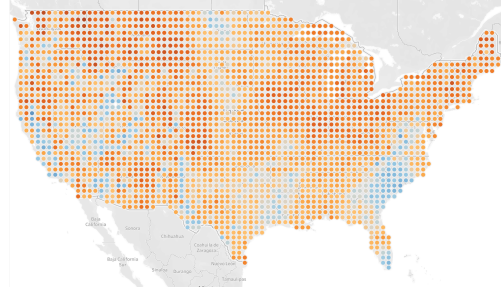

(c) March

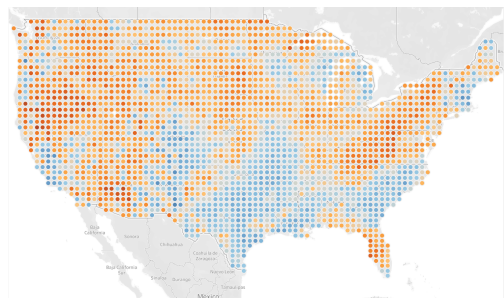

(f) June

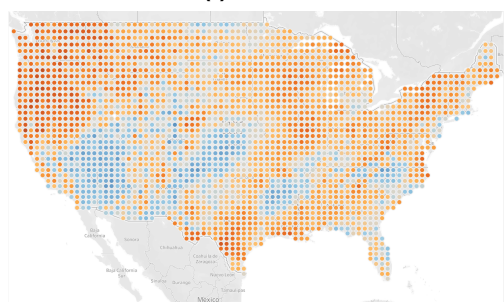

(i) September

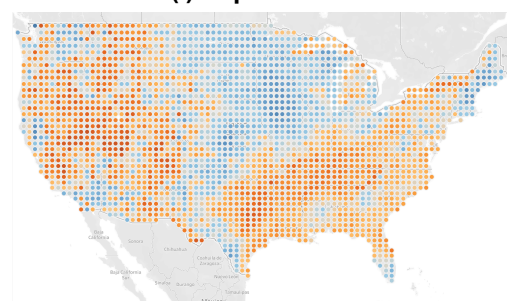

(I) December

Figure Appendix G.1. Daily-averaged complementarity (represented by the Pearson correlation metric) per month in 2013 in the contiguous United States. Red indicates negative correlation $(-1)$ and blue indicates positive correlation $(+1)$. 


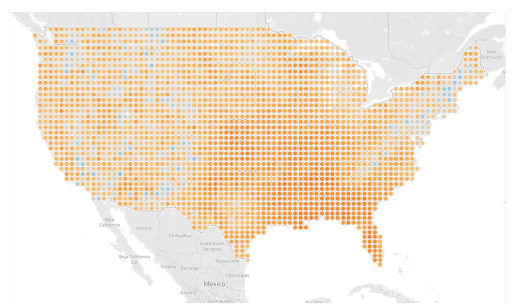

(a) January

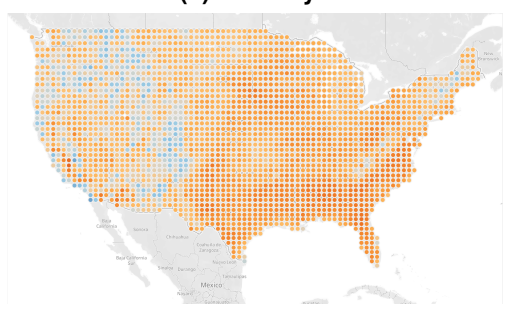

(d) April

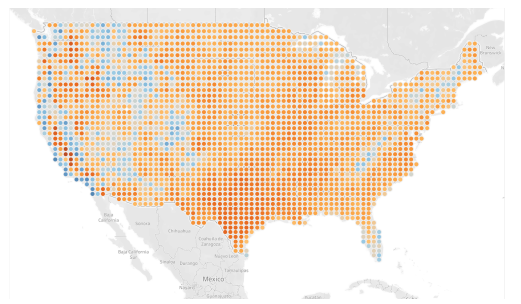

(g) July

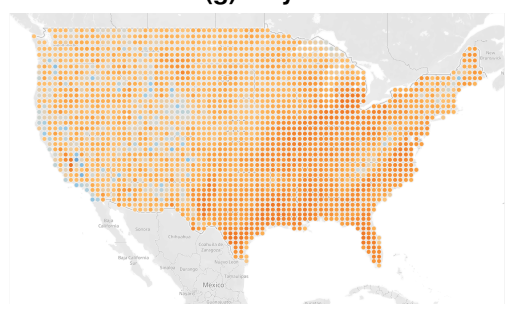

(j) October

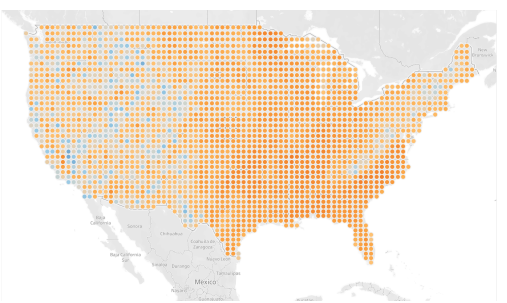

(b) February

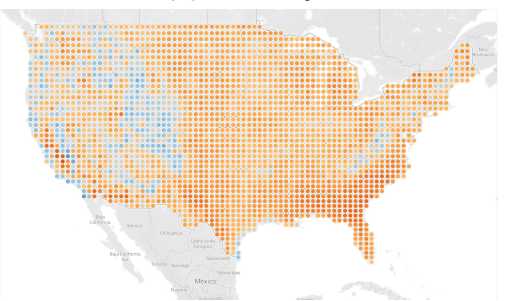

(e) May

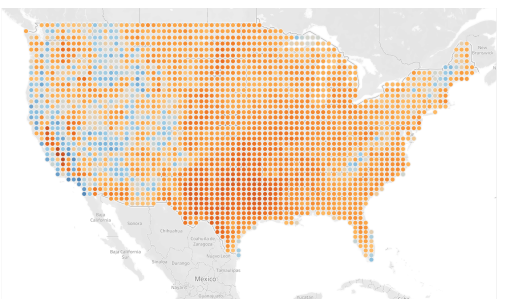

(h) August

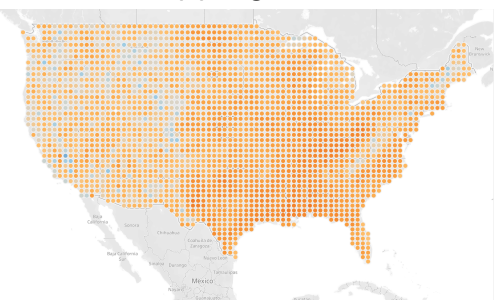

(k) November

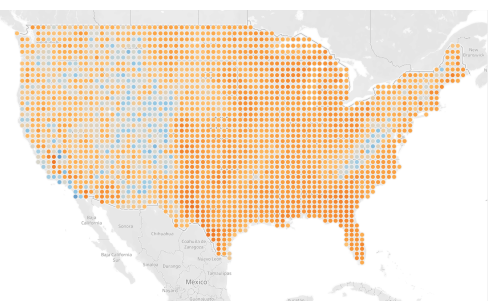

(c) March

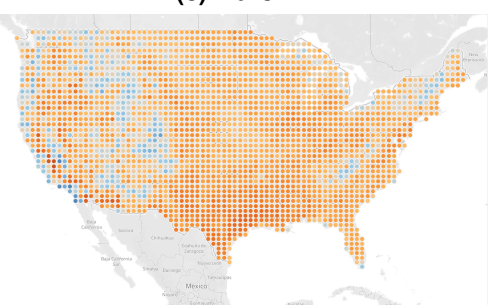

(f) June

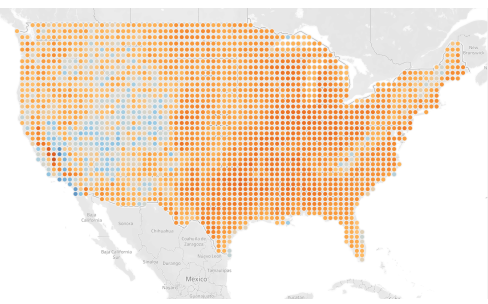

(i) September

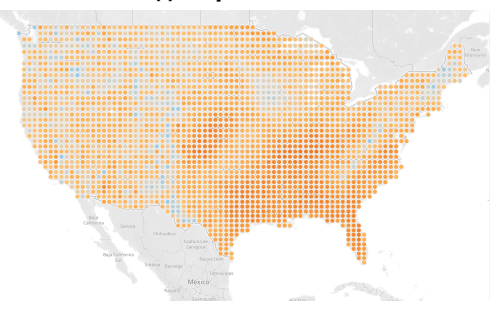

(I) December

Figure Appendix G.2. Hourly-averaged complementarity (represented by the Pearson correlation metric) per month in 2013 in the contiguous United States. Red indicates negative correlation (-1) and blue indicates positive correlation (+1). 


\section{Appendix H Complementarity per Month, Hawaii}

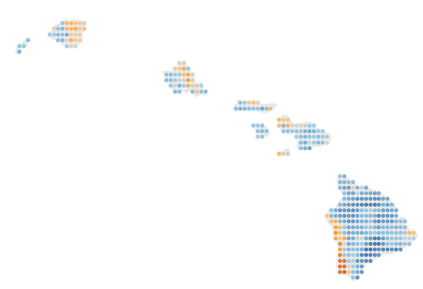

(a) January

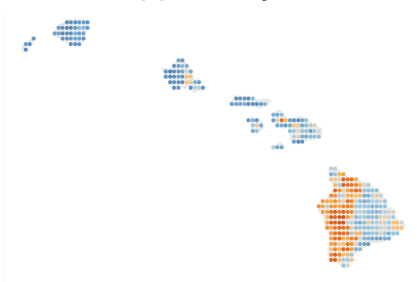

(d) April

풀

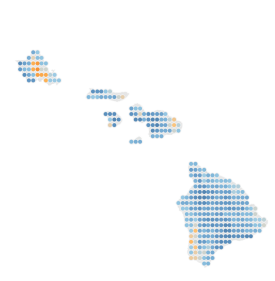

(g) July

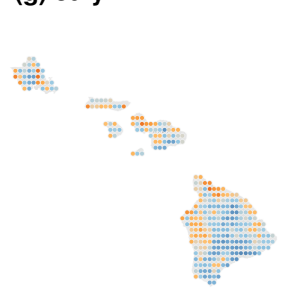

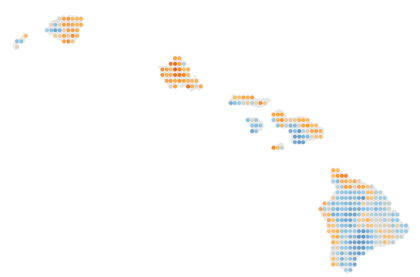

(b) February
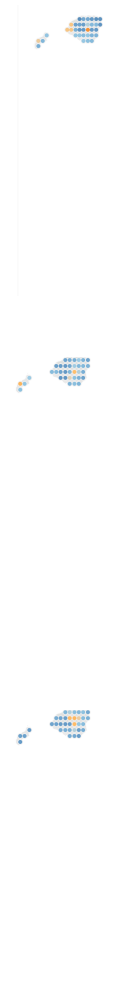

(e) May

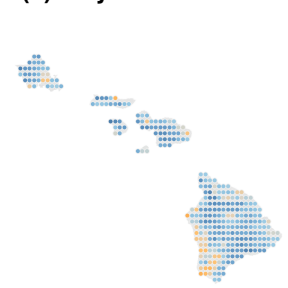

(h) August
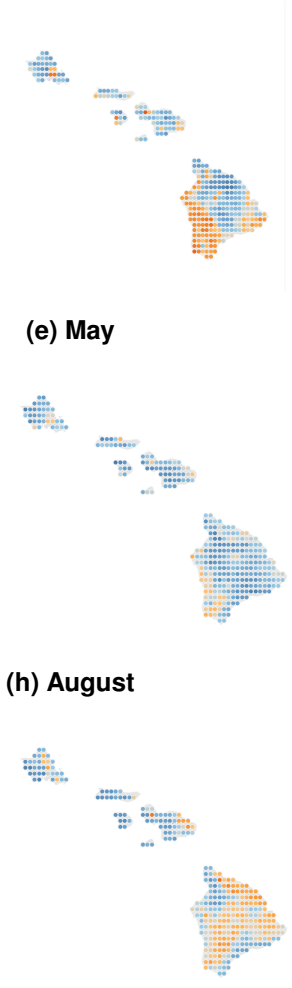

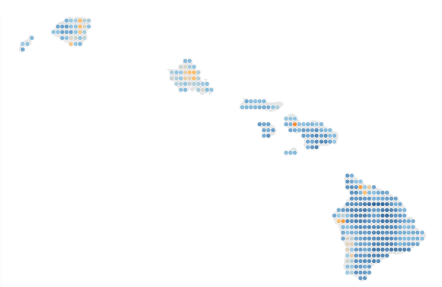

(c) March

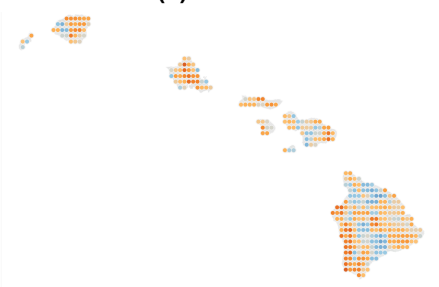

(f) June

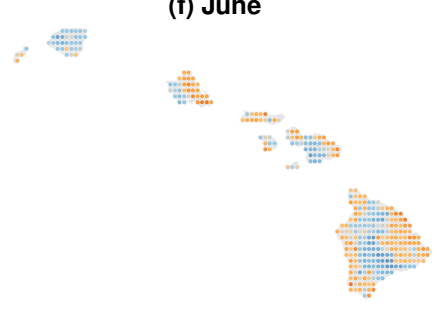

(i) September

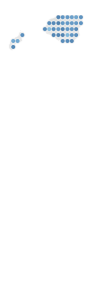

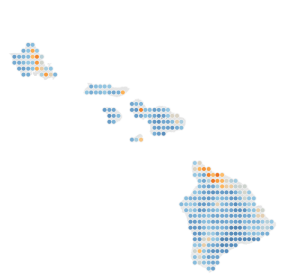

(I) December

(j) October

(k) November Figure Appendix H.1. Monthly, daily-averaged complementarity (represented by the Pearson correlation metric) for 2013 in Hawaii. Red indicates negative correlation (-1) and blue indicates positive correlation (+1). 

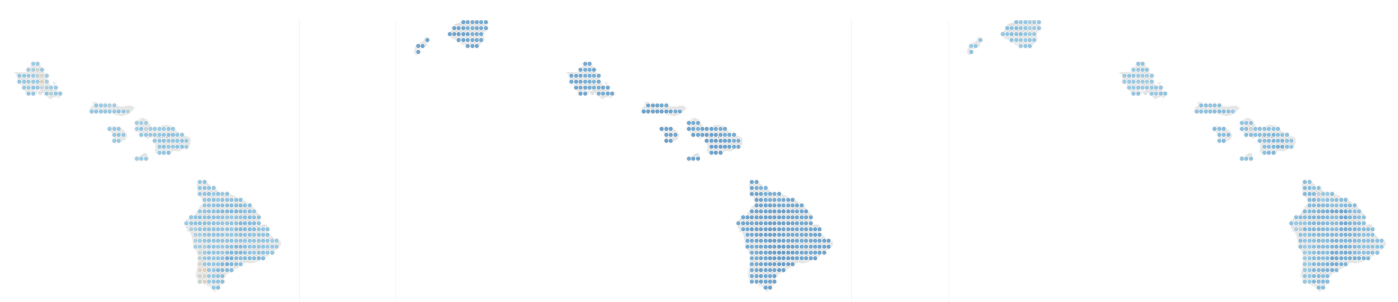

(a) January

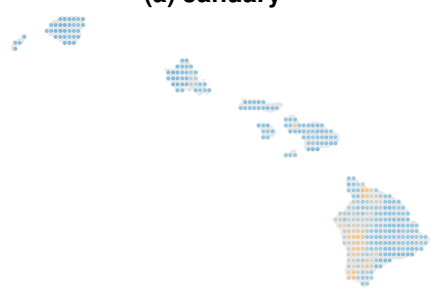

(d) April

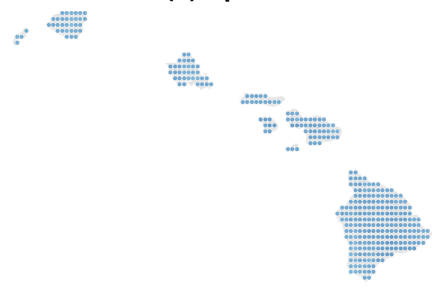

(g) July

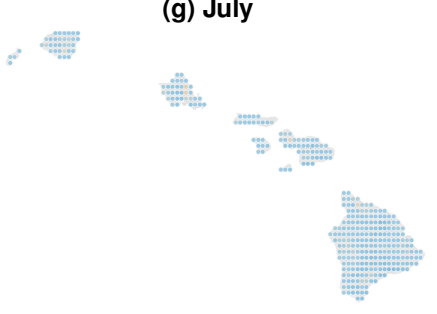

$\begin{array}{ll}\text { (j) October } & \text { (k) November }\end{array}$

(e) May
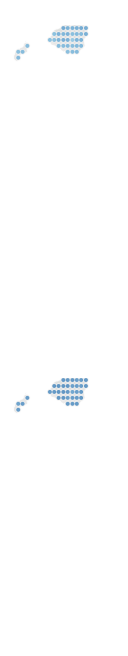

(b) February
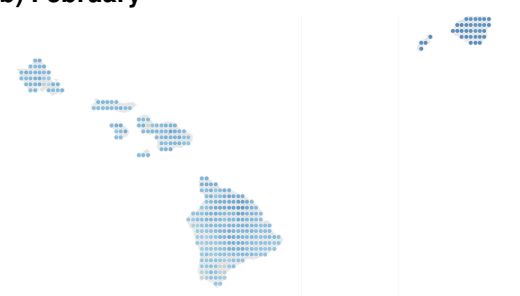

(c) March

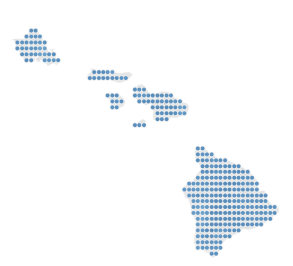

(f) June
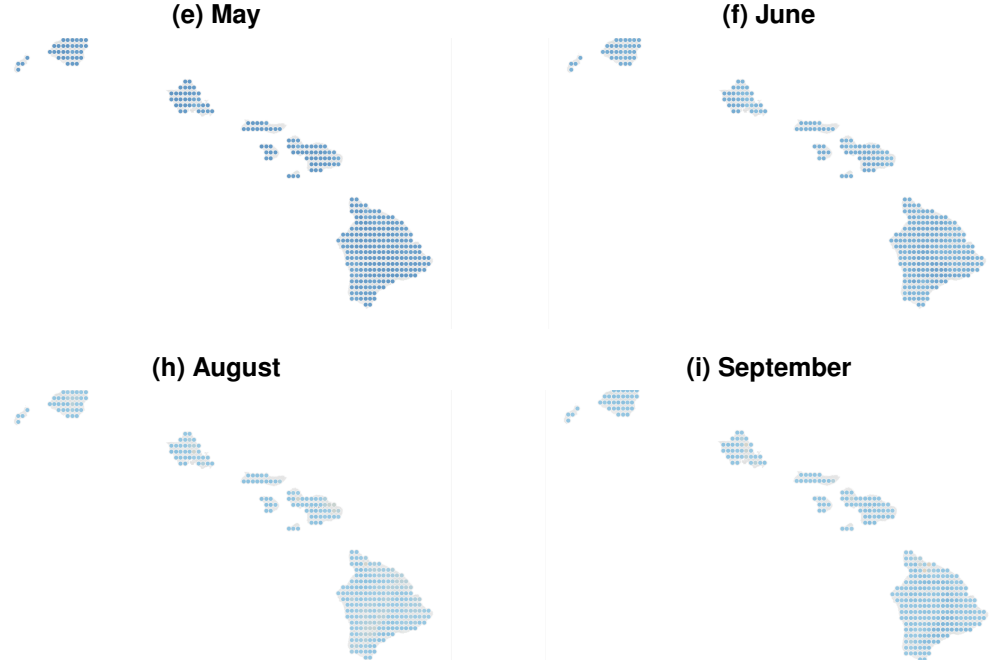

(h) August
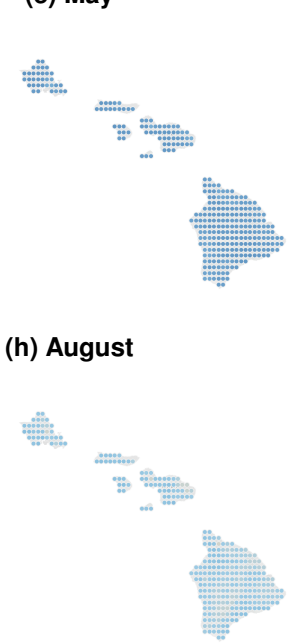

(i) September

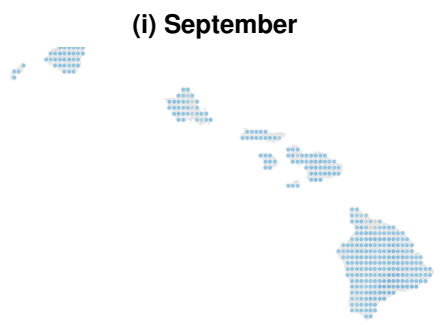

(I) December
Figure Appendix H.2. Monthly, hourly-averaged complementarity (represented by the Pearson correlation metric) for 2013 in Hawaii. Red indicates negative correlation (-1) and blue indicates positive correlation (+1). 


\section{Appendix I Complementarity per Month, Alaska}

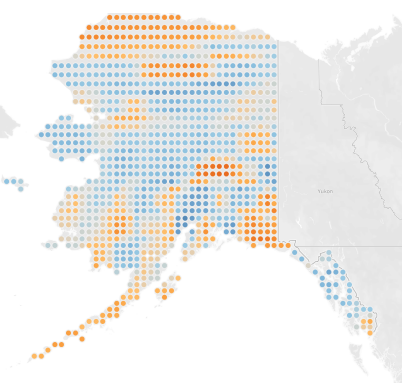

(a) January

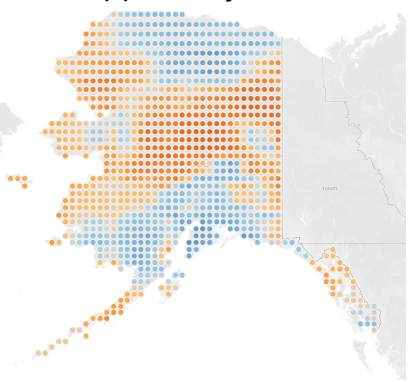

(d) April

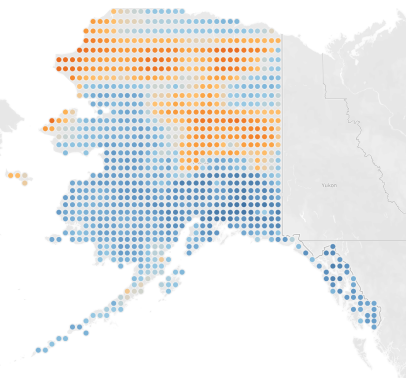

(g) July

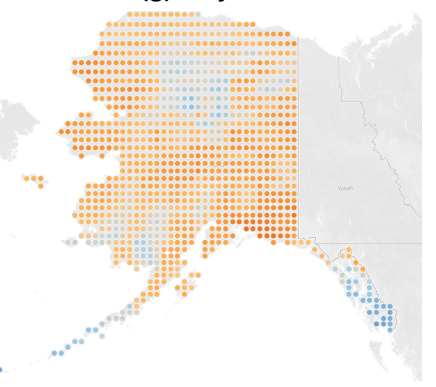

(j) October

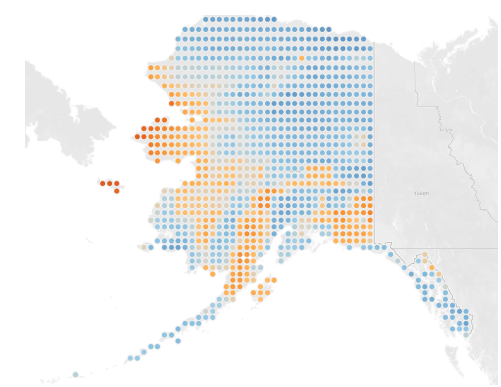

(b) February

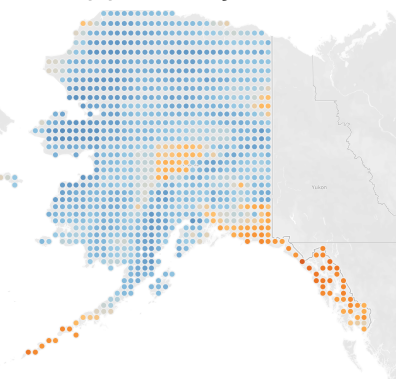

(e) May

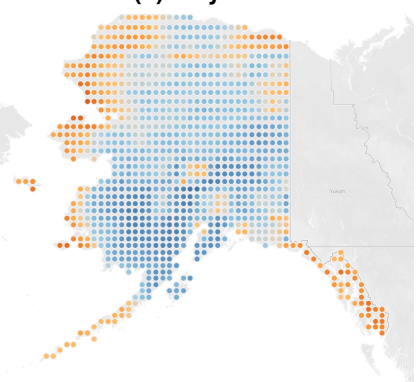

(h) August

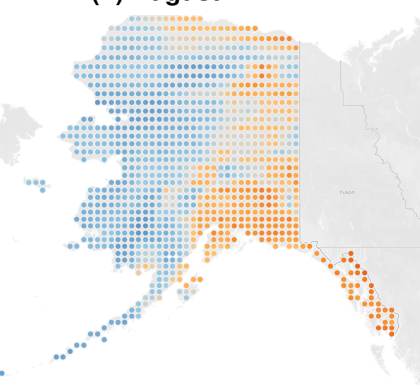

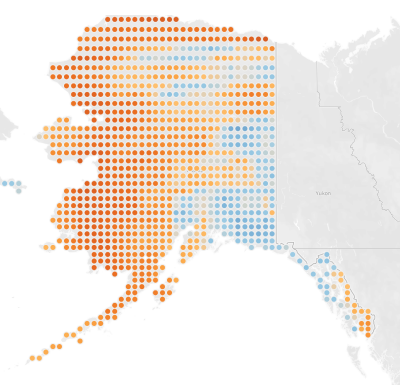

(c) March

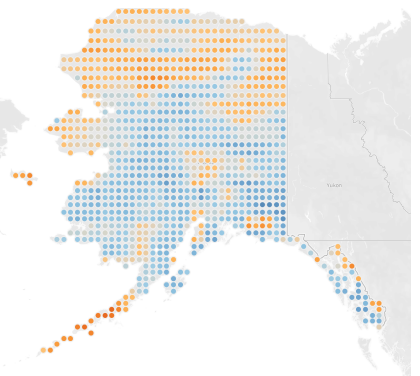

(f) June

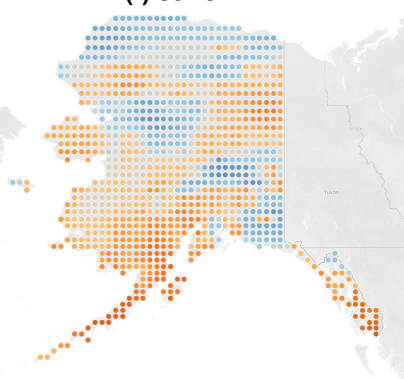

(i) September

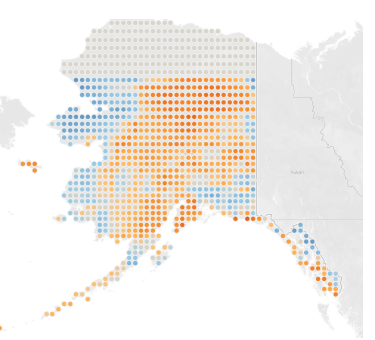

(I) December

Figure Appendix I.1. Daily-averaged complementarity (represented by the Pearson correlation metric) per month for 2013 in Alaska. Red indicates negative correlation (-1) and blue indicates positive correlation (+1). The gray area in December signifies the days in which there is 1 hour or less of sunlight, resulting in a null Pearson $r$ value. 


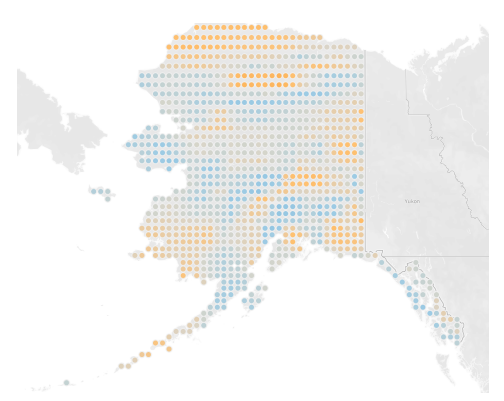

(a) January

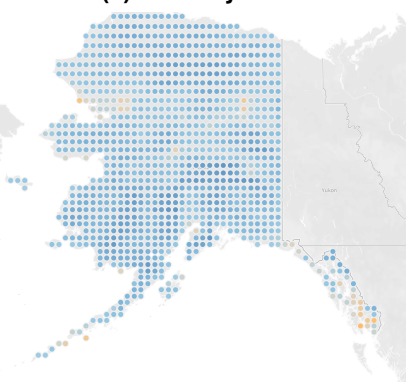

(d) April

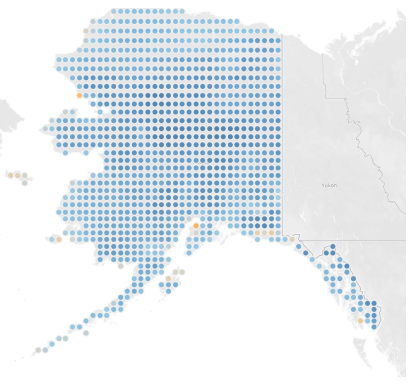

(g) July

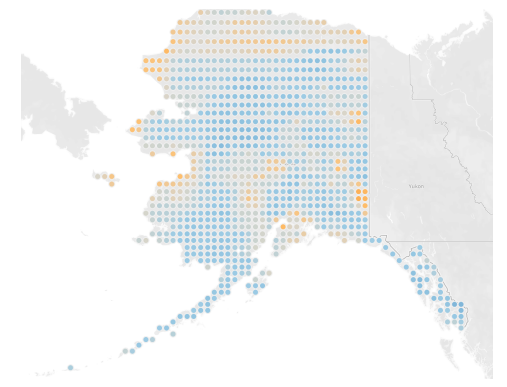

(j) October

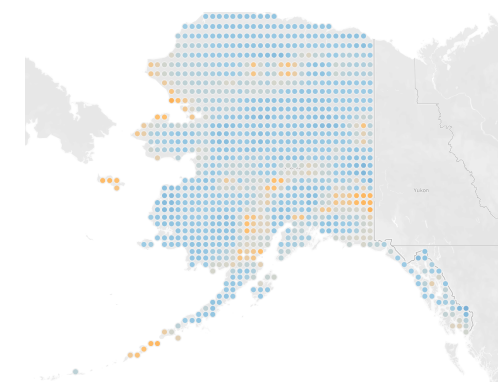

(b) February

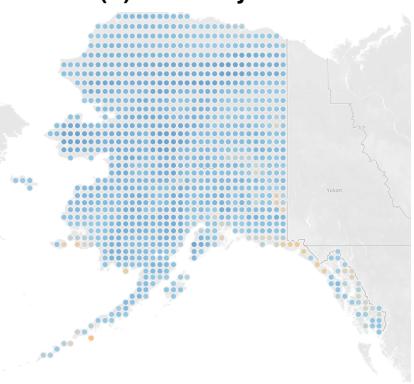

(e) May

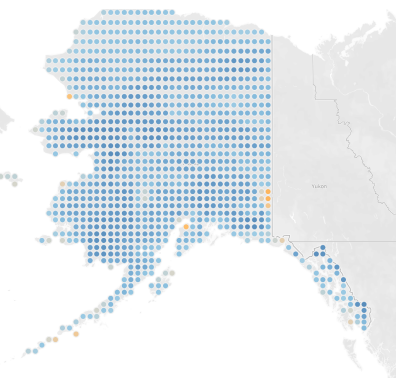

(h) August

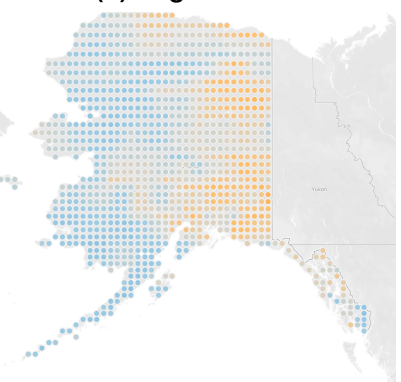

(k) November

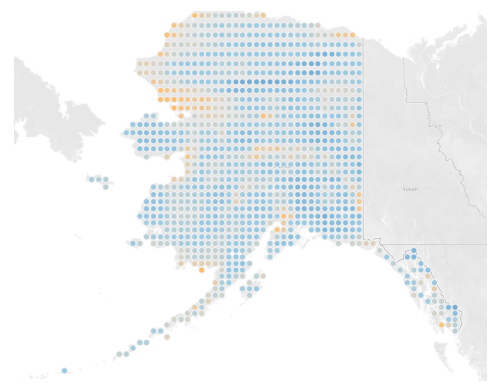

(c) March

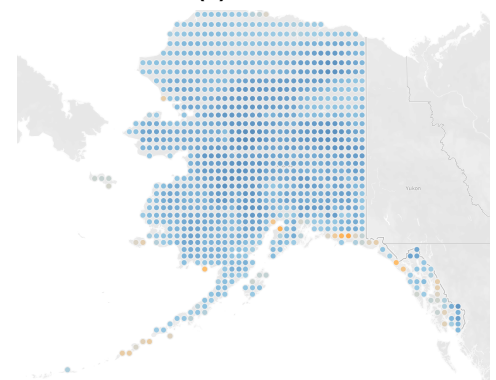

(f) June

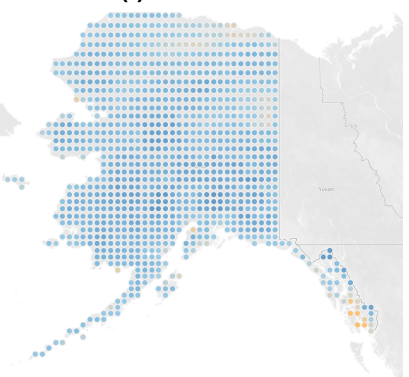

(i) September

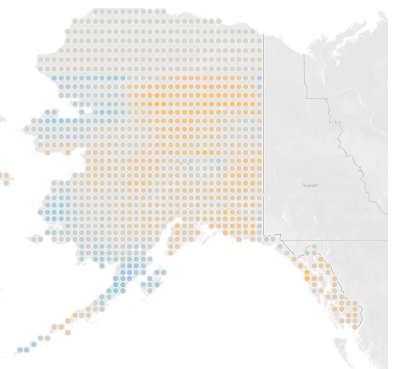

(I) December

Figure Appendix 1.2. Hourly-averaged complementarity (represented by the Pearson correlation metric) per month for 2013 in Alaska. Red indicates negative correlation (-1) and blue indicates positive correlation $(+1)$. The gray area in December signifies the days in which there is 1 hour or less of sunlight, resulting in a null Pearson $r$ value. 